This is the final peer-reviewed accepted manuscript of:

O. Andrisano et al., "The Need of Multidisciplinary Approaches and Engineering Tools for the Development and Implementation of the Smart City Paradigm," in Proceedings of the IEEE, vol. 106, no. 4, pp. 738-760, April 2018.

The final published version is available online at DOI: 10.1109/JPROC.2018.2812836

Rights / License:

The terms and conditions for the reuse of this version of the manuscript are specified in the publishing policy. For all terms of use and more information see the publisher's website.

This item was downloaded from IRIS Università di Bologna (https://cris.unibo.it/)

When citing, please refer to the published version. 


\title{
The Need of Multidisciplinary Approaches and Engineering Tools for the Development and Implementation of the Smart City Paradigm
}

\author{
Oreste Andrisano, Ilaria Bartolini, Paolo Bellavista, Andrea Boeri, Luciano Bononi, Alberto Borghetti, \\ Armando Brath, Giovanni Emanuele Corazza, Antonio Corradi, Stefano de Miranda, Fabio Fava, \\ Luca Foschini, Giovanni Leoni, Danila Longo, Michela Milano, Fabio Napolitano, \\ Carlo Alberto Nucci, Gianni Pasolini, Marco Patella, Tullio Salmon Cinotti, \\ Daniele Tarchi, Francesco Ubertini, Daniele Vigo
}

\begin{abstract}
This paper is motivated by the concept that the successful, effective, and sustainable implementation of the Smart City paradigm requires a close cooperation among researchers with different, complementary interests and, in most cases, a multi-disciplinary approach. It first briefly discusses how such a multidisciplinary methodology, transversal to various disciplines such as Architecture, Computer Science, Civil engineering, Electrical, Electronic and Telecommunication engineering, Social science and Behavioral science, etc., can be successfully employed for the development of suitable modeling tools and real solutions of such socio-technical systems. Then, the paper presents some pilot projects accomplished by the authors within the framework of some major EU and national research programs, also involving the Bologna municipality and some of the key players of the Smart City industry. Each project, characterized by different and complementary approaches/modeling tools, is illustrated along with the relevant contextualization and the advancements with respect of the state of the art.
\end{abstract}

Index Terms - Agent Based Simulation, Citizen Participation, Crowdsensing, Decision Support Systems, E-mobility, Environmental Actions, Historic buildings, Information and communications, Integrated Design Approach, Intelligent transportation system, Mobile Communications, Real-time Data Analysis, Smart City, Smart Grid, Smart Lighting, Smart Navigation.

\section{INTRODUCTION}

$\mathrm{T}$ HE Smart City paradigm has recently emerged as a revolutionary approach to tackle the challenges posed by modern urban areas [1-3]. Rapid urbanization, buildings aging,

The following EU and Italian Ministry of Education, University and research (MIUR) projects inspired the present paper: ePolicy (EU FP7 2011-2014), DAREED (EU FPT7 2012-2015), Pegasus (Italian Ministry for Economic Development, 2009-2012), Vicom (MIUR, 2002-2005), SOFIA (EU, 2009-11), IoE (EU, 2011-2014), E2SG (EU, 2012-15), Arrowhead (EU, 2013-2017), KISADAMA (EU, 2013-2016), 3ENCULT (EU FP7, 2010-2014), SMooHS (EU FP7 2008-2011), RIGERS (MIUR, 2012), ROCK (EU, 2017-2020), Gaucho (MIUR PRIN 2015). Reference to the relevant websites is given in the text.

O. Andrisano, A. Borghetti, G. E. Corazza, F. Napolitano, C.A. Nucci, G. Pasolini, D. Tarchi, and D. Vigo are with the Department of Electrical, Electronics and Information Engineering, University of Bologna (e-mail: \{oreste.andrisano; alberto.borghetti; giovanni.corazza; fabio.napolitano; vehicular traffic, energy provision, personal safety and data security are, amongst others, some of the issues that place serious strains on citizens' quality of life and health ${ }^{1}$ as well as on the economic and environmental sustainability of human activities. The topic is certainly of importance as the population living in urban areas is expected to double by 2050 [4].

By leveraging on information and communication technologies (ICTs), Smart Cities promise to make more efficient the use of physical infrastructure and resources, to learn and adapt to changing circumstances more effectively, and to engage effectively with citizens in local governance.

However, such ambitious goals can be achieved only thanks to advanced data management, security, and enabling technologies [5], through a multi-disciplinary and multistakeholder approach, and by a close cooperation among researchers with different, complementary interests and innovation attitude. These last two aspects represent the main focus of this paper. Indeed, increasing the smartness of a city involves heterogeneous infrastructures, concerning telecommunications, roads, power grids, as well as residential and public buildings (e.g., [6,7]). A comprehensive and holistic perspective is needed so to envision different components of the urban systems as a unitary living body in which ICTs play the role of connective tissue between citizens, facilities, physical infrastructures and governance [8].

The expected reward of such a process is an inclusive environment where, thanks to innovative technical solutions, citizens experience healthier, safer and more efficient

carloalberto.nucci; gianni.pasolini; daniele.tarchi; daniele.vigo\}@unibo.it). I. Bartolini, P. Bellavista, L. Bononi, A. Corradi, L. Foschini, M. Milano, M. Patella and T. Salmon Cinotti are with the Department of Computer Science and Engineering, University of Bologna (e-mail: \{ilaria.bartolini; paolo.bellavista; luciano.bononi; antonio.corradi; luca.foschini; michela.milano; marco.patella; tullio.salmoncinotti\}@unibo.it). A. Boeri, G. Leoni and D. Longo are with the Department of Architecture, University of Bologna (e-mail: \{andrea.boeri; giovanni.leoni; danila.longo\}@unibo.it). A. Brath, S. de Miranda, F. Fava, F. Ubertini are with the Department of Civil, Chemical, Environmental, and Materials Engineering (e-mail: \{armando.brath; stefano.demiranda; fabio.fava; francesco.ubertini \}@unibo.it).

${ }^{1}$ In this paper we shall deliberately disregard health issues as to this topic is addressed in the companion paper by Bertini et al. 
conditions, in terms of energy and water saving. Turning such a vision into reality requires competences related to multiple disciplines: here we shall make particular reference to Computer Science, Civil-Architectural engineering, Electrical, and ICT engineering, although we are aware that Smart Cities is a multidisciplinary subject that cannot be dealt with exhaustively in an engineering journal.

As observed in [1], "there is no single generally acceptable definition for a Smart City, but several efforts are emerging to try and capture the multidimensional and multidisciplinary nature of what a Smart City represents". In view of the above, instead of providing a further general definition of Smart City, which is beyond the scopes of this paper, we feel it worthier to concretely support the concept of its multidisciplinary nature by making reference to some major research projects we have carried out. The projects dealt with will be grouped in three main areas, namely i) Integrated infrastructures and processes, ii) Sustainable urban mobility and iii) Sustainable districts and urban environments.

Although a commonly accepted model of Smart City is not yet available, we thought it appropriate to introduce a functional diagram of the Planning and Operation of Smart City processes to which all implementations/projects/modeling tools proposed in the paper can make reference. To accomplish that, we need to make reference first to a specific Smart City paradigm concerning the Engineering/Computer Science area: this is shown in Fig. 1. In it, the interaction of different types of data and the three pillars the Smart City concept relies on (namely infrastructures, processes and people), represents the basis for providing services to several application domains (e.g. ICT Systems, e-Policy, Cyber security, etc.).

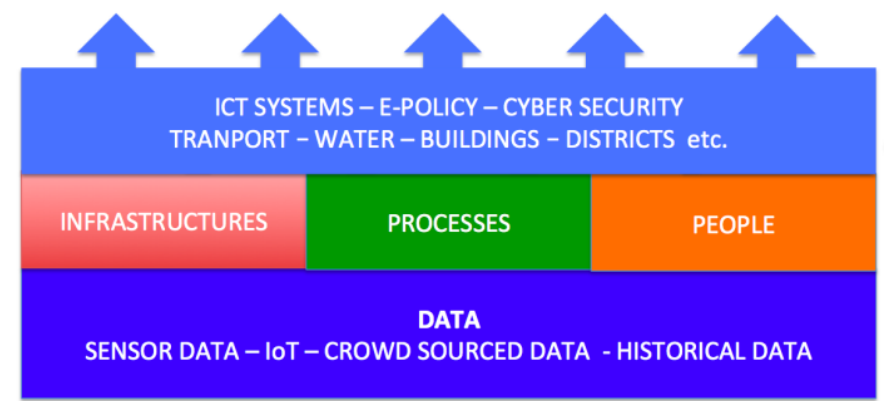

Fig. 1. Reference Smart City paradigm concerning the Engineering/Computer Science area: interaction between data and infrastructures, processes and people is depicted.

Then, for each of the above mentioned application domains reported in Fig.1, namely ICT systems, e-Policy, Cyber security, Transportation, Districts, etc., one can apply mutatis mutandis the Smart City functional planning and operation scheme shown in Fig. 2, or part of it. The active, fundamental, roles of users - citizens - is highlighted by means of a dedicated block. There is also a strong coupling among different application domains, which stresses the need of multidisciplinary tools. Think for instance at the transport infrastructure and the electric power grid: the relevant planning and operation phases need to be conceived and managed consequently in a scenario of high penetration of e-mobility.

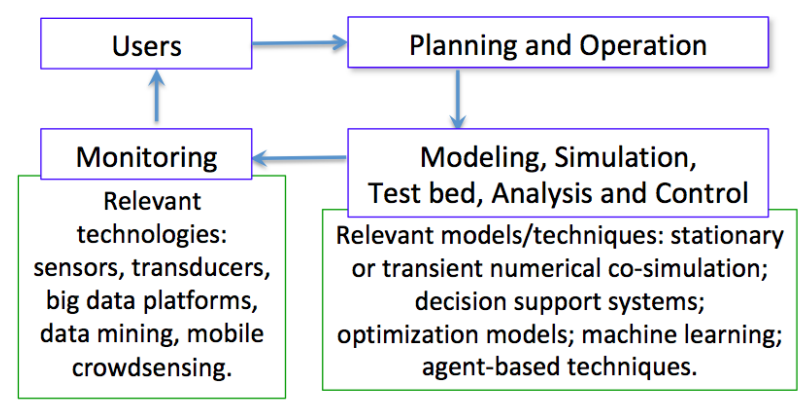

Fig. 2. Functional diagram of the Planning and Operation of Smart City processes as a function of citizens (users) active participation. The roles of the Simulation, Analysis and Control phases with relevant enablers (Modeling and Technologies) are embodied.

The paper is organized as follows: in Section II the fundamental role of ICT systems within Smart Cities will be illustrated. Section III is devoted to the description of the above mentioned research projects carried out by the authors concerning the area of Integrated infrastructures and processes. Section IV concerns the area of Sustainable urban mobility, while Section V concerns the area of Sustainable districts and urban environments. Sections III, IV and V all serve at both showing the essential role of multidisciplinary/multi partners approach and at illustrating how different application domains can be properly instantiated within the functional scheme of Fig. 2. Conclusive remarks will be given in Section VI.

\section{THE ROLE OF ICT SYSTEMS}

As mentioned in the Introduction, for the development/implementation of the Smart City paradigm, the role of ICT is believed so crucial, that we felt it appropriate to devote a separate Section to the role of ICT systems.

As it will be shown in the following sections, it is possible to realize that a Smart City environment is characterized by the interconnectivity of several entities: it is indeed only through the interconnection of a multitude of devices, having diversified characteristics in terms of data generation, data processing or data relaying, that it is possible to evolve from a fragmented scenario of multiple disconnected clusters of devices to a uniform integrated environment where the different devices are collaborating. As suggested by Batty [3], to understand cities, we must view them not simply as places in space, but as systems of networks and flows. Thus, we can consider the ICT infrastructure as a framework that represents the technological nervous system allowing the networks and flows of the city to afford a better urban way of life.

By analyzing the technology systems underlying a Smart City framework, it is possible to identify three principal types of devices having different roles [9]:

- the sensors, able to acquire different types of data regarding the users and the environment, transmitting a large amount of information (possibly at low data rate) by means of the ICT infrastructure;

- the nodes that compose the distributed ICT infrastructure, where neighboring devices can collaborate through resource sharing, becoming an integral part of the network; 
- the outputs, composed by the final users, which become aware of results and are consequently able to make decisions, or become actuators without the need for human intervention.

On the other hand, an ICT infrastructure can be seen as built by three main components that should be used by the different devices:

- the communication component, which embraces all the communication functions by assuming to have multiple heterogeneous networks interacting among them;

- the processing component, which allows to optimize the processing load among the different entities located at the core or at the edge, by exploiting centralized and distributed cloud infrastructures and by considering also their processing capabilities;

- the storage component that is used for both big data and processing code storage, and that can be placed in a distributed or centralized framework, at either the core or the edge of the network.

\section{INTEGRATED INFRASTRUCTURES AND PROCESSES: RESEARCH AT THE UNIVERSITY OF BOLOGNA}

\section{A. Joint Computing and Communication Management for Smart Cities Applications}

The envisioned Smart City environment is characterized by the presence of a pervasive double-layer ICT infrastructure: a communication layer and a computing layer that should mutually interact in order to enable Smart City services, by leveraging on the three communication, processing and storage components.

At the same time, each application to be considered in a Smart City environment can be characterized through relevant requirements that should be satisfied to leverage the ICT infrastructure. Among others, the most important seem to be:

- Latency: the amount of time required by a certain application between an event occurrence and the event being acquired by the system

- Energy consumption: the amount of energy consumed for performing a certain application, with attention to the tasks to be performed on the mobile devices

- Throughput: the amount of data transfer required in a certain time interval by a specific application to be reliably executed in the Smart City environment

- Computing: the amount of computing operations requested by a certain application

- Exchanged data: the amount of input, output, and code information to be transferred by means of the wireless network

- Storage: the amount of storage space required for storing the sensed data and/or the processing application

- Users: the number of cooperating users needed to achieve reliable service

Despite all this heterogeneity, it is still possible to define a unified framework where the various resources and requirements are mutually interacting [9]; the overall performance of such a framework can be modeled as a cost function whose optimization can be achieved by resorting to proper algorithms. Such cost function, that can be seen as the network overall Quality of Service (QoS), is modeled in order to, on one side, take into account the requirements introduced by each application and, on the other side, leverage on the three components previously introduced whose management and optimization allows to respect the requirements. This approach is particularly important in the planning phase, following the methodology defined in the Section I.

Such an approach is particularly challenging in the envisioned Smart City scenario, represented in Fig. 3, where the processing effort could be implemented either in a centralized way by resorting the cloud approach or a distributed way by resorting to the recently introduced Mobile Edge Computing $[10,11]$, Cloudlet [12,13] and Fog Computing [14,15] schemes. Both approaches have also a big impact on the underlying communication layer since the amount of data to be transported in both data and control plane are greatly affected. This means that a tight integration of computing and communications layers allows to tradeoff between them, introducing the necessity of algorithms able to optimize the processing loads by taking into account a centralized and high performance computing solution along with a distributed low performance solution and, on the other side, the impact on the required data rate in the backhauling.

The previously introduced approach based on the definition of a suitable QoS function allows to fit the specific application to a given scenario in order to optimize the allocation of the resources to the different processing and communication entities.

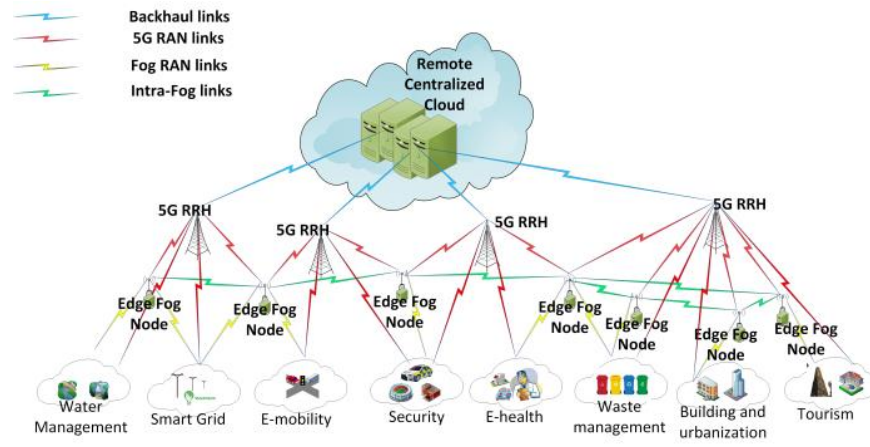

Fig. 3. ICT infrastructure and its interaction with some of the core components of a Smart City - Waste management; Smart Grid; E-mobility; Security; Ehealth, Waste management; Building and Urbanization and Tourism - through Cloud and Fog infrastructures.

This leads to the definition of several methodologies and techniques that allow to implement a suitable operational phase by following the methodology defined in the Section I.

As an example, in the literature several approaches have been proposed based on multiobjective optimization, Multiple Integer Linear Programming, metaheuristics solutions, etc. [1619]. Among other approaches, in [16] a metaheuristic solution based on randomized algorithms, aiming at selecting the best access point to be used in a heterogeneous network environment in order to cope with a target QoS, is proposed. The effectiveness of the solution has been proven through numerical optimization, by comparing the optimal solution with the proposal and showing that in return for a limited performance degradation the proposed solution can be achieved in a short amount of time, leading to the possibility of realizing real-time implementations, which are crucial for practical adoption. 
Alongside the optimization of the resources for respecting the application requirements, recently a parallel approach has been envisaged that considers the ICT infrastructure itself as an application to be optimized, and not only the comprehensive cluster of resources that allows the applications to be performed. This has extended the focus towards the inclusion of the control plane alongside the data plane as a target to be considered. To this aim the Cloud Radio Access Network (C-RAN) [17] concept has been introduced as a framework to consider how the different functions of a Radio Access Network (RAN) could be shared among different processing entities in order to help to respect the different QoS requirements of each application type.

The most recent advance within this framework is toward what is often referred as Fog Computing and Networking [18], whose aim is that of creating a distributed computing infrastructure at the edge of the network in order to decrease the latency towards the centralized cloud infrastructure. While similar approaches have been considered, as the cloudlet or the mobile edge computing, the fog computing and networking solution seems the one having the most advantages. The foreseen fog computing and networking infrastructure should work in a transparent way for the users' applications and allow to automatically select the target device to be used for data processing. By exploiting the most recent advances in the networking area (e.g. Software Defined Networking (SDN), Network Function Virtualization (NFV)) it should be possible to select in a flexible way the nodes implementing fog functionalities to perform the wanted tasks. In such a way, the Fog infrastructure can be seen as an extension of the cloud infrastructure towards the edge in a hierarchical way for implementing a flexible approach. Similarly, the fog computing infrastructure is foreseen to be used not only for optimizing the data plane but also the control plane by introducing the concept of Fog-RAN (F-RAN) [19], where fog devices are able by themselves to manage the control plane of the RAN for respecting the users' requirements [20] (see Fig. 3).

As a matter of fact, in the PRIN 2015 Gaucho project ${ }^{2}$ the goal is that of studying and assessing the possibility of implementing a Fog Communication and Networking infrastructure; in that project the focus was mainly to the energy saving objective where two main scenarios have been considered, both related to the Smart City environment: an emergency scenario where multiple nodes are deployed in the environment with the goal of having a fast and low latency response, and a Vehicular scenario where multiple vehicles should interact among them.

\section{B. Sustainable Policies}

Governing Smart Cities implies understanding, controlling and managing a tightly coupled set of complex socio-technical systems. Urban traffic, energy, water and waste management, communication networks, health services are only few examples of such socio-technical systems, involving interactions between complex infrastructures, man-made processes, natural phenomena, multiple stakeholders, and human behavior. On top of this complexity, we have access to

\footnotetext{
${ }^{2}$ Green Adaptive Fog Computing and Networking Architecture, Research Project Financed by the Italian Minister of Education, University and Research (MIUR).
}

data sets of unprecedented scale and accuracy about these systems.

In this context, policy makers are called to perform a deep analysis of these systems, of available data sets, to define, assess and compare alternative scenarios of policy plans and instruments from an environmental, social and economic perspective. Referring to Fig. 2 we are here discussing about the Planning component where monitoring is performed by analyzing data and is aimed at providing policy planning targets that are achieved by strategic plans created, compared and assessed through analysis and simulation tools.

To support policy makers in their decision process [21,22], a tight integration of data analytics techniques is needed: descriptive, predictive and prescriptive analytics tools are aimed at extracting models describing the system from data, at predicting its future dynamics and at selecting optimal scenarios in terms of policy options and instruments.

The ePolicy project [23], funded by the EU and involving Universities, research centers, Small and Medium Enterprises (SMEs) and the Emilia Romagna Region as public body, has been aimed at providing policy makers with decision support systems covering the whole ex-ante policy making life cycle in the energy sector:

1) the planning step where strategic objectives are set in line with EU and national guidelines;

2) the Strategic Environmental Assessment (SEA) stage where environmental indicators are considered to understand the impacts of the devised plan;

3) the implementation phase where policy instruments are defined to meet the strategic objectives in the policy agenda;

4) the citizen and stakeholder participatory process.

Multi-criteria optimization techniques [24] cover the first two stages, devising mathematical models that describe the system in terms of decisions to be taken, financial, environmental and budget constraints, objective functions and metrics to optimize multiple, possibly contrasting, criteria. The output of the planning step is a set of alternative policy planning scenarios along with their impact on economic and social aspects. Environmental indicators are inserted in the model to enable the SEA process so as to identify significant impacts of the planning decisions. This would allow the Emilia Romagna Region to more efficiently implement its circular economy strategy also at the level of its major cities. To craft these models we benefit from machine learning techniques that enable the data-driven construction of optimization model components, through Empirical Model Learning [25]. Data have been provided by the Emilia Romagna Region and the Environmental Protection agency. The output of the SEA process provides a policy maker with a clear view on the environmental effects expected by the alternative planning scenarios proposed in the first step.

Supporting the implementation phase $[26,27]$ is probably the most challenging step. We have to use techniques for simulating social interactions and behavior. Agent-based 
modeling and simulation is probably the most promising technique for mimicking complex systems that cannot be described by closed formulas, namely equations representing the system dynamics. The tuning and validation process are crucial to produce realistic emerging behaviors. In ePolicy, agent-based modeling and simulation has been used to forecast the impact of energy implementation policy instruments to support the adoption of renewable energy sources. These instruments cover investment grants, financial and rotation funds, feed in tariffs and tax exemption. For this domain, not only financial aspects should be taken into account to mimic the dynamics of the energy market, but also social aspects related to imitation, trust in government, perceived bureaucracy that heavily affect the human behavior. The social simulator designed and implemented in ePolicy from the University of Bologna and the University of Surrey, has very closely followed the real trend of renewable energy sources (RES) cumulative adoption in the Emilia Romagna region both on the training set (years 2007-2013) and on the test set (years 20142016) as depicted in Fig 4.

Finally, ICT could also support citizen participation to craft public policies, by providing policy makers with opinion mining tools [28] that automatically extract from blogs and forum statements, argument, opinions on a specific policy topic. In all cases decision support systems, properly fed by machine learning on available data and simulation techniques enable informed and transparent decision making for governing Smart Cities.

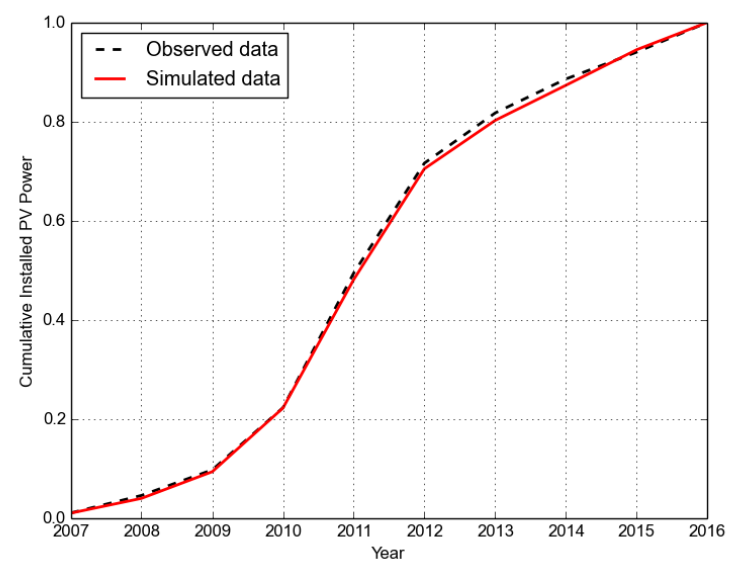

Fig. 4. Observed and simulated cumulative RES adoption in Emilia Romagna (adapted from [26]).

\section{Citizens Active Participation Through Mobile Crowd Sensing}

The large availability of smart devices with significant computing and sensing capabilities, combined with the capillary readiness of communication infrastructures has boosted the diffusion of platforms for Mobile Crowd Sensing (MCS). For instance, the recently released iPhone $\mathrm{X}$ hosts a high definition camera and can accomplish facial recognition aboard; smartphones, apart being a sensing platform themselves, are also able to interact with Internet of Things (IoT) objects in their surroundings.
MCS is a citizen-centric support that allows people to actively contribute in the Smart City management loop, volunteering for the execution of given monitoring and sensing activities (called tasks in the following). In particular, MCS is a paradigm and an ICT-enabled integrated infrastructure solution (see Fig. 1) for distributed gathering of heterogeneous sensing data from pocket devices used by citizens (i.e., crowdsourced sensor data); it fits within the Monitoring block in the Bologna Smart City management loop shown in Fig. 2. MCS enables the accurate tracing of world-related information and (physical) activities of people, by taking advantage of their willingness to cooperate towards a continuous data harvesting process. Such a function is feasible and highly effective in Smart Cities areas where people density is high and potential participants bring almost constantly with them their smartphones [29]. There are already several MCS systems and some good surveys about MCS systems available (e.g., [30]).

There are several research efforts addressing the different MCS facets separately; in the following, without any pretense of being exhaustive we report some examples. Vita is a system that stresses the relevance of providing crowdsensing as a service integrated with usual software services and supports sensing task assignment based on user profiles (see [31] for further details). As an open issue, Vita completely lacks support for advanced assignment policies for those tasks that are geolocalized, e.g., based on user movement history. Matador is a crowdsensing software that focuses on context-awareness to optimize impromptu task assignment while minimizing battery consumption [32]. However, Matador does not support proactive approaches able to leverage past mobility history to tailor effectively future task assignments. Medusa is a framework that proposes domain-specific programming language and algorithms to provide high-level abstraction to define MCS tasks [33]. At the same time, Medusa lacks task assignment support of geolocalized tasks and, similarly to Matador and Vita, it also lacks support for signal processing and machine learning to automatically perform high-level inferences concerning user activities. All above systems have been tested on a small user base and for a short duration.

The Mobile Middleware group of the Computer Science and Engineering department of the University of Bologna has realized a very significant MCS platform and long-running experiment, called ParticipAct, funded by the Emilia Romagna POR-FESR 2007-2013 regional funds, inside the research activity of the CIRI ICT Technopole of Bologna. ParticipAct, with a wide international breadth, allowed to experiment the full MCS monitoring potential in cooperation with and over the Smart City of Bologna. To accomplish that it has implemented by contracting a telco operator to provide more than 200 university students for more than two years with a Samsung Galaxy S3 Mini and a flat data connection (as initial incentives to voluntary participation)

Our MCS solution, ParticipAct, is a seminal and original effort that makes a significant step forward, in that it proposes a holistic solution to all aforementioned problems by tackling the whole stack of technical and social problems related to crowdsensing. Along that direction, ParticipAct introduces 
significant advancements to the state of the art. First, it answers the need by community/Smart City managers to enable the monitoring of areas still not covered by fixed monitoring infrastructures (noise pollution sensors, surveillance cameras, etc.). Second, citizens not only execute passive sensing actions running in background over their phones, but can also actively participate through their actions that may eventually impact and modify the physical world (citizens as monitors, but also actuators in the Smart City). The resulting scenario is novel and original, because users are not only consumers of information, but also producers, called sometimes prosumers; that role enables new forms of participation and e-citizenship. Third, the ParticipAct dataset is the first-of-its-type for the high number of users involved (more than 200) and for duration (more than two years); that required also to acquire the consent of the Italian responsible for personal data protection (Garante per la Protezione dei Dati) and then individual consents for the gathering of individual personal data.

Although the ParticipAct target is Smart City monitoring, the ParticipAct MCS process reference model, shown in Fig. 5, covers itself all the main blocks of the general Smart City management loop presented in Fig. 2. The ParticipAct loop starts when city managers have a new sensing need to collect data over a Smart City area not covered by any fixed sensing infrastructure. Then, in order to ease task scheduling to volunteers, ParticipAct uses all available historical data in the profile of user behavior within the system, such as their GPS traces and the success ratio of completed task assignments, to profile volunteers and Smart City areas. These profiles allow selecting the best people to involve in the MCS process and to quantify the minimal number of people to contact, so to (probabilistically) obtain a certain number of data samples. That is also crucial to grant the scalability of the proposed MCS solution by dynamically identifying and activating only those data streams strictly needed to obtain sensing data of interest. These differentiated MCS strategies and policies, toward overall MCS optimization, are novel and very significant, especially if regarded as a real and seminal over-the-city MCS living lab experiment [29].

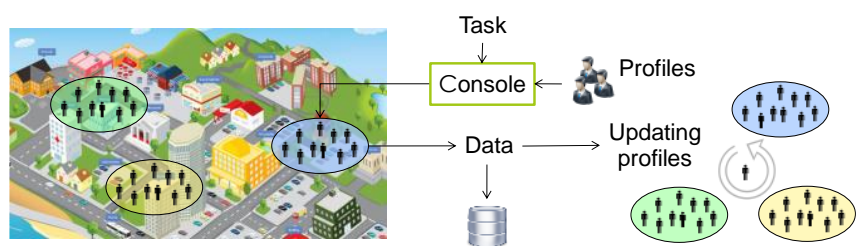

Fig. 5. MCS process model and deployment over Smart Cities.

Concerning technical challenges, much effort was also devoted to the design of the core sensing library, called MoST (Mobile Sensing Technology [34]), so to grant minimal intrusion and power consumption at the user smartphone, as confirmed by the satisfactory volunteers' user experience.

Last but not least, we underline the transnational breadth of the ParticipAct project [34]. In fact, ParticipAct, led by the University of Bologna, with significant contributions by New Jersey Institute of Technology, USA, and Universidade do Estado de Santa Catarina, Brazil, along with associated experimentations in Italy and the Americas, is one of the largest international living lab for active participation of citizens in collaborative tasks [29,35,36]. Fig. 6-(a) and Fig. 6-(b) show an example of results achievable with ParticipAct used to track citizen mobility patterns in Bologna (Italy) and Florianopolis (Brazil).

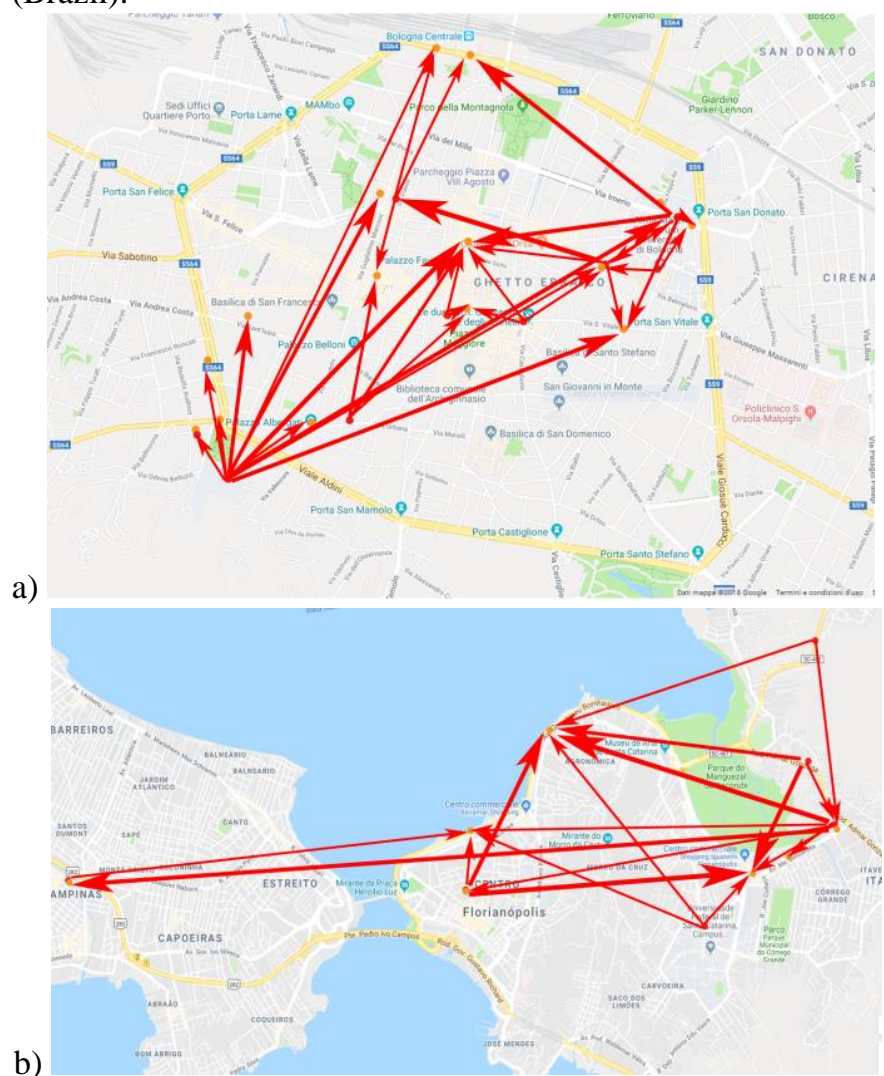

Fig. 6. Mobility of citizens between points of interest automatically evaluated from mobility traces obtained through the ParticipAct app in (a) Bologna and (b) Florianopolis. The generated map allows a city administrator to observe how people move and commute throughout their daily routines, using colors to conveniently represent detected trajectories according to the period they fall into the day, and thickness to visualize the number of people commuting (the thicker the line the higher the number of people moving).

\section{Real-Time Analysis of Big Data in Cyber Security}

Real-time analysis of multimedia (MM) streams coming from sensors distributed in the environment for the security of citizens (e.g. automatic alerts generation caused by the presence of suspected people in public places such as airports, museums, and metro stations) is another topic for which a theoretical approach can be illustrated and compared with existing ones. Indeed, the huge amount of information produced by Smart Cities represents a formidable asset to face menaces to security, but is rarely exploited due to the lack of appropriate data management technology (and law-related aspects, which are deliberately disregarded in this paper) [37]. Big Data platforms provide opportunities for the management and analysis of large quantities of data; however, the services they provide are often too raw, since their focus is on issues of fault tolerance, increased parallelism, etc. In order to effectively use such architectures for advanced applications, an additional software layer is thus needed [38].

In this sub-Section we illustrate a framework for the real-time 
analysis of massive MM streams, where data come from multiple data sources (such as sensors, cameras, etc.) that are widely located over the territory, with the final aim to discover new and hidden information from data sources output, as they occur, thus with very limited latency. Such huge amount of information can therefore be exploited in order to contribute to the monitoring of safety in Smart Cities (see the lower-left block in Fig. 2).

We feel it worth illustrating $\mathrm{RAM}^{3} \mathrm{~S}$ (Real-time Analysis of Massive MultiMedia Streams) i.e. a software framework for the automated real-time analysis of MM streams. $\mathrm{RAM}^{3} \mathrm{~S}$ has been successfully applied $[39,40]$ to the study of face detection for the automatic identification of "suspect" people: this can be useful, for example, in counter-terrorism, protection against espionage, intelligent control of the territory, or smart investigations. Although $\mathrm{RAM}^{3} \mathrm{~S}$ has been instantiated for a very specific task, it is independent of the specific at hand, thus demonstrating its wide applicability. Other applications include the recognition of suspicious behavior or urban traffic control from videos, human actions or gesture, audio events.

In Fig. 7 we show the general operation of a stream analysis system: data coming from the stream are "compared" with those stored in a knowledge base, which have been obtained from a previous training phase to represent interesting patterns to be searched in the data stream. Whenever the data in the stream are deemed relevant, for example, because they are sufficiently similar to one of the data stored in the knowledge base, this is signaled by the system (this might be used to raise an alarm or to feedback the system with appropriate instructions).

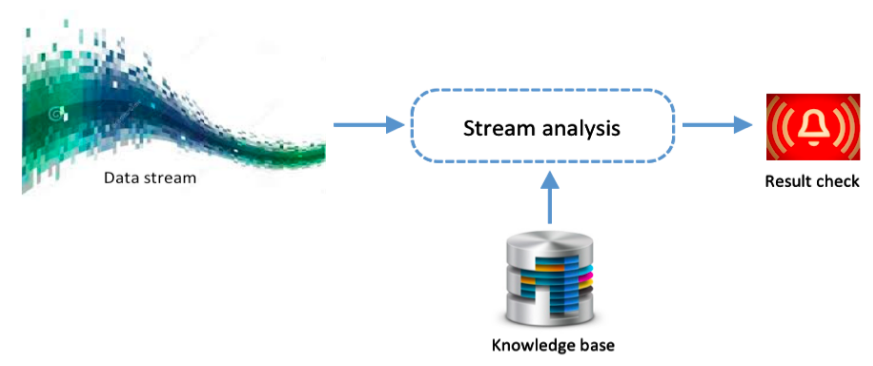

Fig. 7. Analysis of data stream.

Although the problem of stream analysis is not novel per se [41], its application in presence of several MM streams is questionable, due to the very nature of MM data, which are complex, heterogeneous, and of large size. This makes the analysis of MM streams computationally expensive, so that, when deployed on a single centralized system, computing power becomes a bottleneck.

The "traditional" way to address such issues is exploiting faster, larger, better hardware, that is to scale up the underlying system. The shortcomings of this type of scalability are due to the inherent limitations of a single centralized computer (without mentioning costs). Another (orthogonal) possibility is to scale out the underlying system, by adding extra machines to share the computational burden. However, this introduces issues of distributing the complex computation among nodes, resource contention, etc., which should be solved to effectively scale out the system.
To allow efficient analysis of massive MM streams, we advocate scaling out the underlying system by using platforms for Big Data management. The use of already established techniques for the analysis of Big Data has the clear advantage of making stream analysis techniques applicable in a distributed environment, shifting the focus away from low-level issues of fault tolerance, replication, data storage/transfer, etc.

The $\mathrm{RAM}^{3} \mathrm{~S}$ framework facilitates the implementation, on top of existing platforms for management of Big Data streams, of any data stream analysis technique working as in Fig. 7. In this way, researchers can avoid paying the additional cost of writing the ad-hoc software layer required for interfacing their technique to the underlying platform. The thesis we purport here is the following: by exploiting the $\mathrm{RAM}^{3} \mathrm{~S}$ framework together with a platform for Big Data, any traditional (centralized) system for data stream analysis can be effectively scaled out with little effort. The use of the proposed framework can thus effectively allow the application to huge data volumes of algorithms for MM stream analysis, that were originally conceived for a centralized scenario only and whose extension to a distributed context is not immediate. To the best of our knowledge, this is the first attempt to tackle, from a general perspective, the analysis of massive multimedia streams.

Our assumption is that the incoming MM stream can be represented as a sequence of individual MM objects (MMObjects): the analysis of each MMObject instance [42], continuously repeated over time produces the result. The goal of this reductionist approach is not to be an all-inclusive representation of MM stream analysis, but (1) to be general enough to encompass the vast majority of stream analysis algorithms and (2) to be simple enough in order to make interfacing with the underlying Big Data platform as easy as possible.

Fig. 8 shows the results of an experiment performed on a cloud environment comparing the speedup obtained when using $\mathrm{RAM}^{3} \mathrm{~S}$ on top of three different Big Data platforms, namely Spark, Storm, and Flink, when detecting faces of known people from several concurrent video streams, like those coming from cameras displaced on the territory. The graphs show the speedup (computed as the ratio of sustainable input rate with $n$ machines to sustainable input ratio with 1 machine) obtainable when increasing the number of machines $\mathrm{n}$ using above platforms: as proved by Fig. 8, we achieve almost linear scalability (ideal line) in all cases, which demonstrates the efficiency of the proposed approach.

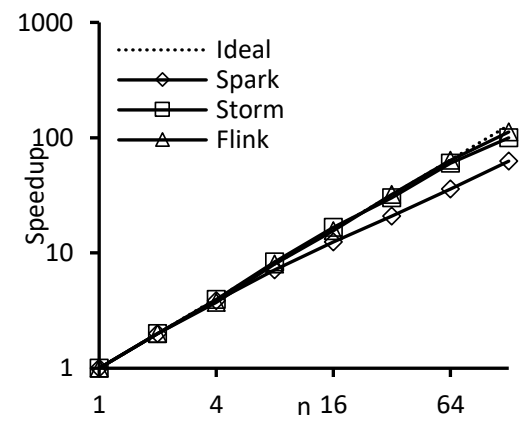

Fig. 8. Speedup on sustainable input rate as a function of the number of machines $(n)$ in cloud environment (Adapted from [39]). 


\section{Sustainable URban Mobility: RESEARCH AT THE UNIVERSITY OF BOLOGNA}

\section{A. Heterogeneous Network for Smart Navigation}

Different research activities were carried out by Wilab researchers in the field of vehicular mobility since the early European initiatives PROCOM [43] and DRIVE [44] (late '80s) in the area of ICT for intelligent transportation systems. More recently, the Wilab team has been involved in several projects in the area of ICT for Smart Cities. In particular, we refer to ViCom (2002-2004), concerning immersive indoor navigation exploiting suitable localization systems, TRIP (2007-2009), aimed at providing the best combination of trains, buses and metros to get public transportation users to their destination, and PEGASUS (2009-2012), aimed at implementing an intelligent platform for e-services and smart navigation. In the framework of PEGASUS, a hybrid software-hardware platform was built by Octotelematics in cooperation with the University partners to exploit the information collected by sensing and transmitting units on board of vehicles.

The following research areas were investigated through an integrated approach, which jointly considered all aspects affecting the service effectiveness (from the reliability of communications to the perceived quality of service):

- ICT technologies for smart mobility [45,46];

- performance of vehicle-to-vehicle $(\mathrm{V} 2 \mathrm{~V})$ and vehicle-toroadside (V2R) communications [47-49];

- virtual traffic lights for enhanced safety at road intersections [50].

Whenever possible, analytical investigations are pursued to fully model the phenomena of interest. However, the analytical approach is rarely feasible in Smart Cities scenarios, owing to the high complexity of technologies involved as well as the large number of aspects to be simultaneously considered (propagation conditions, data traffic characteristics, user behaviors, etc.). In most cases, therefore, the realization of testbeds and the implementation of software simulators [51,52] are the only strategies to get an insight into such complex systems. Examples of both approaches are presented in the following, which are focused on communication infrastructures for vehicular mobility. They refer, therefore, to the Infrastructures box of Fig. 1 as well as to the simulation and test bed activities highlighted in Fig. 2.

Simulative approach: Nowadays, an increasing number of vehicles traveling worldwide is equipped with on board units (OBUs), featuring sensors and wireless communication devices that periodically collect and transmit their position and speed. The same task is also accomplished by navigation applications running on modern smartphones.

These raw data are transmitted through the cellular network to a remote-control center, which infers the travel time of each road segment traveled by equipped cars. Transmitting such information back to vehicles in real-time allows on-board navigators to dynamically choose the best route in order to reduce the traveling time. Data are thus exchanged through vehicle-to-infrastructure (V2I) communications, being the cellular network the communication infrastructure.

Since the number of vehicles equipped with OBUs is continuously and rapidly increasing, as well as the the number of smartphones running navigation applications, the burden for the cellular network is expected to dramatically increase, possibly leading to a degradation of the quality of service experienced by users, also including those not involved in vehicular-oriented services.

These considerations motivated us to investigate this scenario, in order to assess both the benefits on the vehicular mobility and the critical aspects for the cellular network. This investigation required the realistic simulation of vehicles movements, as well as a complete simulation of the cellular network, both in the uplink and in the downlink.

For this reason, a simulation platform [52] integrating the vehicular traffic simulator VISSIM [53] and the simulation platform for heterogeneous interworking networks (SHINE) [54] has been developed. The former reproduces the dynamic of vehicular mobility, taking into account its driving factors, such as road layouts, number of lanes, vehicles acceleration and decelerations, speed limits as well as the presence of traffic lights and one-way roads, whereas the latter is a wireless network simulator developed at Wilab, which takes into account the whole communication network architecture, from the application layer to the physical layer. The two simulators were jointly integrated to reproduce all aspects of the smartmobility scenario, thus providing a realistic insight into performance and critical aspects.

We focused our attention, in particular, on short-range V2V and V2R communications based on the IEEE $802.11 \mathrm{p}$ technology, which could be used instead of cellular (i.e. V2I) communications [47] when transmitters and receivers are close enough. Our simulation tool was thus oriented to a scenario where low-cost roadside units (RSUs) are available (e.g., in correspondence of properly chosen light poles or traffic lights), which are equipped with IEEE $802.11 \mathrm{p}$ transceivers for V2R communications. V2V and $\mathrm{V} 2 \mathrm{R}$ short range communications are exploited whenever possible to aggregate data collected by vehicles $(\mathrm{V} 2 \mathrm{~V})$ and reach the RSUs (V2R), whereas V2I is used by each OBU to autonomously transmit collected data if short range communications are not available in time. Such a flexible solution is in accordance with the technological integration envisioned in $5 \mathrm{G}$ communication networks.

The road-network layout of the reference scenario consisted of a portion $\left(1.6 \times 1.8 \mathrm{~km}^{2}\right)$ of the medium sized Italian city of Bologna with eight possible locations for the RSUs, as depicted in Fig. 9. In all cases, RSUs were placed at intersections for better coverage and to take advantage of the power supply already available for traffic lights. 


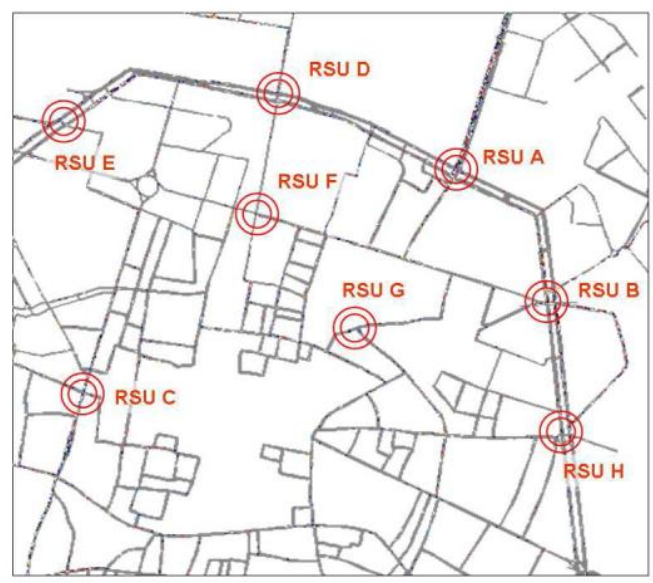

Fig. 9. RSU locations in the considered scenario (adapted from [49]).

Simulation results show that even a scarcely dense deployment of RSUs leads to a significant reduction of cellular resource occupation, approaching $100 \%$ with a high density of $\mathrm{V} 2 \mathrm{~V}$ and $\mathrm{V} 2 \mathrm{R}$ enabled vehicles [49]. In particular, having denoted with $D_{R}$ the amount of cellular resources that can be saved through the use of short range transmissions and with $d_{t x}$ the maximum transmission range, Fig. 10 shows $D_{R}$ as a function of $\mathrm{d}_{\mathrm{tx}}$ under normal traffic conditions (corresponding 150 vehicles $/ \mathrm{km}^{2}$ ), varying the fraction $\delta$ of vehicles equipped with OBUs and the number of RSUs deployed in the reference area. Results show that the use of V2V and V2R is very effective, even when a single RSU (RSU A) is properly positioned in a large area. In particular, Fig. 10 shows that when all the RSUs are deployed, with $\mathrm{d}_{\mathrm{tx}} \geq 200 \mathrm{~m}, \mathrm{D}_{\mathrm{R}}$ approaches the $100 \%$ when $\delta=1$ or $\delta=0.5$, exceeding the $90 \%$ even with $\delta=$ 0.1 . If a single RSU is deployed, similar results are possible only with a higher OBU density ( $\delta=0.5$ or 1$)$; nonetheless, even with a single RSU and $\delta=0.1, \mathrm{D}_{\mathrm{R}}$ is still significant (from $20 \%$ to $50 \%$ ).

$V 2 V$ and V2R testbed: An experimental test-bed, carried out by means of real OBUs hosting the IEEE 802.11p technology, was also developed. Fig. 11 shows the equipment used on board of each vehicle. It included, in particular:

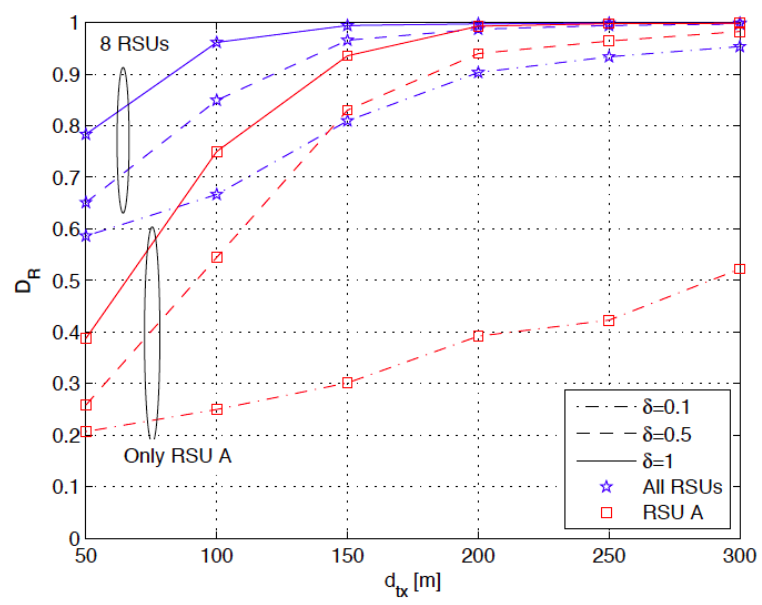

Fig. 10. Delivery rate $D_{R}$ versus transmission range $d_{t x}$, assuming eight RSUs or a single RSU, and a percentage of vehicles equipped with the OBU $\delta$ equal to $0.1,0.5$, or 1 (adapted from [49]).

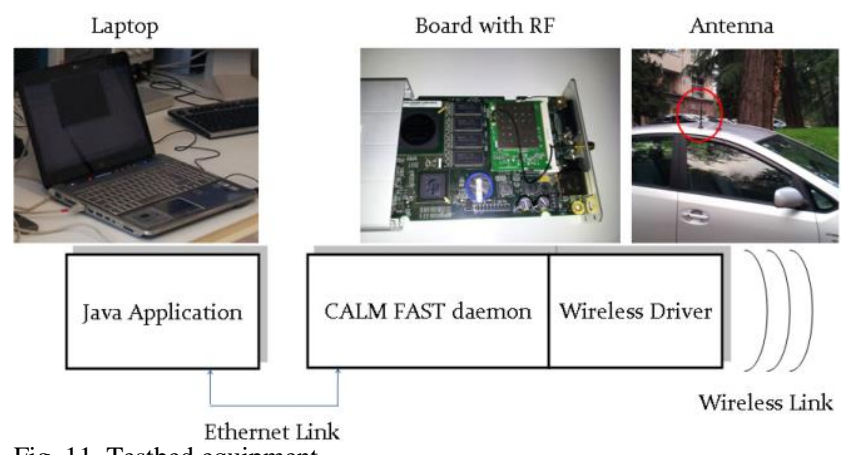

Fig. 11. Testbed equipment.

- an Alix3d3 board produced by PC Engines with a compact flash memory and a Mikrotik RouterBOARD R52-350 (which was provided with an Atheros AR5414 chipset);

- an antenna connected to the RouterBOARD.

- a laptop connected to the Alix3d3 board through an Ethernet link;

- a GPS device connected to the Alix3d3 board;

The linux based OpenWrt operating system was running on the Alix $3 \mathrm{~d} 3$ board. To enable the use of IEEE 802.11p, the open source software provided by the Grand Cooperative Driving Challenge (GCDC) was used.

A transmission power of $20 \mathrm{dBm}$ was adopted in the $5.89 \mathrm{GHz}$ band. By considering an antenna gain of $4 \mathrm{~dB}$ and the actual implementation losses of $10.5 \mathrm{~dB}$, the real EIRP was limited to $13.5 \mathrm{dBm}$, a value that is significantly lower than the limits given for this application $(33 \mathrm{dBm}$ in Europe and even more elsewhere).

Two cars were equipped with such devices, denoted nodes in the following, and an experimental campaign was carried out in urban scenarios. In order to investigate the packet error rate (PER) each node transmitted broadcast messages (20 packets per second), and the number of missed or wrong packets was counted at the receiver side in a time intervals of 10 seconds.

One of the most relevant experiments concerned two cars randomly moving in an urban area affected by the daily traffic, with some non-line-of-sight conditions. Results are summarized in Fig. 12, where the PER is shown as a function 
of the average distance between the cars. Circles, pluses and asterisks are used to denote the cases of line-of-sight, other vehicles between the testing cars, and buildings and/or trees between the testing cars, respectively.

Results show that for distances lower than $100 \mathrm{~m}$ the reliability of the connection could be satisfactory. For larger distances, instead, the presence of other vehicles obstructing the direct link is the most frequent event, which leads to a degradation of the communication link. It is worth observing, however, that the detrimental impact of such phenomenon can be significantly mitigated allowing each vehicle to act as a relay of received packets, so as to establish multi-hop communications. Further details on other lessons learned through the measurement campaign can be found in [49], which also originated new research fields $[55,56]$.

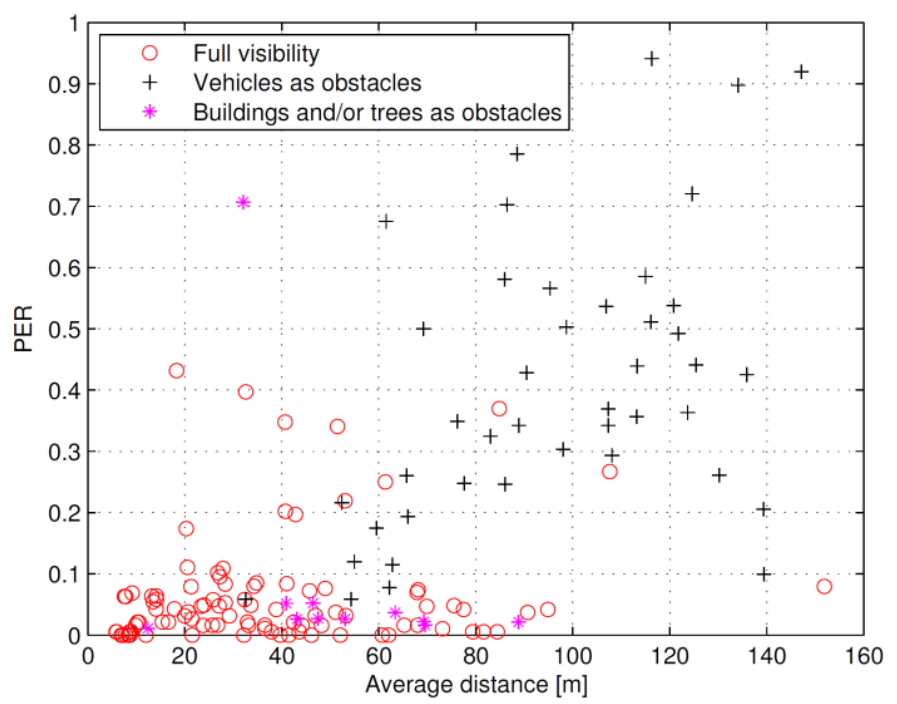

Fig. 12. Scenario with two cars moving randomly in an urban area. PER versus the average distance between the cars.

\section{B. E-mobility and Smart Grid}

Mobility-wise Smart Cities must get ready for the transition to electric mobility. While most manufacturers are in the conditions of bringing plug-in Electric Vehicles (EVs) to the market, the planning and deployment of recharging infrastructures, able to meet users requirements and preserve (or improve) the grid power quality, is still an issue. This research topic is extremely interdisciplinary as it involves grid analysis, traffic analysis and pre-deployment service simulation. The relevant literature is large and encompasses problems of planning, operation and control, in some cases taking also into account interactions with the electricity market. For example [57] presents a technical management and market operation framework for EV integration into electric power systems. An integrated analysis tool that combines vehicle energy demand simulations, a transportation simulation and a power system model combined with a charging control algorithm is presented in [58]. In [59], a Multi Agent System (MAS) for the decentralized EV charging control in a hierarchical management structure is proposed. A recent mixed integer convex programming model is proposed in [60] for the solution of the coupled expansion planning problem for both the electrified transportation network (charging stations and roads) and the power distribution network. Several other different approaches are proposed in the references therein the papers already mentioned.

To address this topic at the Analysis, Simulation and Control level referred to in Fig. 2, this Section is devoted to the trafficgrid-communication co-simulation platform described in [61] that has been used for the analysis of a district of the city of Bologna. To the best of our knowledge, this is the first triple cosimulation platform presented in the open literature.

Fig. 13 shows the main components of the co-simulation platform that integrates i) a mobility simulator suitably adapted to take into account also the use of electric vehicles (EVs) [62], ii) a dynamic simulator of the power distribution network and iii) a realistic communication network simulator specific for a shared Universal Mobile Telecommunications System (UMTS) network. The urban traffic is modeled using the discrete eventbased open source framework for vehicular network simulations VeinS, extended with the models of EVs and charging stations (including the management of the EVs queues); the power distribution network is modeled in the time domain EMTP-RV simulation environment; the simulator of the UMTS mobile communication network is based on the Riverbed Modeler Wireless suite. The interface between the different simulators and the data integration is realized in a very flexible way via a Semantic Information Broker (SIB), i.e. a semantic middleware originated by the European Project SOFIA [63] and improved during the subsequent project related to electric mobility Internet of Energy (IOE) [62].

This platform represents a powerful tool for assessing the effects of the transients caused by the concurrent charging of many electric vehicles on the operating conditions of the MV network and designing countermeasures against the overload of the power network components. As an example, $[61,64]$ present the analysis of a MAS composed, on the one hand, by the intelligent electronic devices (IEDs) installed both at the HV/MV substation and near those critical branches of the network that may be overloaded due to EVs charging and, on the other hand, by the control units, connected to the communication network, each associated to the cluster of EV supply equipments (EVSEs) of a parking lot. When an IED detects an overcurrent condition (in general undervoltage conditions are quite rare in urban MV power networks), it starts to send appropriate congestion indexes to the control units of the EVSE clusters connected to a downstream bus so to reduce the maximum available power for the EVs charging and to counteract the congestion. Each control unit communicates also with each single EVSE of the parking lot in order to allocate among the various charging EVs the maximum power that can be absorbed from the MV network taking into account the EVs specific charging characteristics and requirements. The co-simulation platform allows also for the assessment of the influence of the loss of information (represented by the block error rate) and the latency caused by background traffic in the communication links on the performances of the MAS (see [61,64] for some results relevant to the city of Bologna, Italy, and related discussion). 
Moreover, the platform calculates the daily power flows in the network taking into account the effects of the charging processes as a function of the expected percentage of electric vehicles in the urban traffic flow.

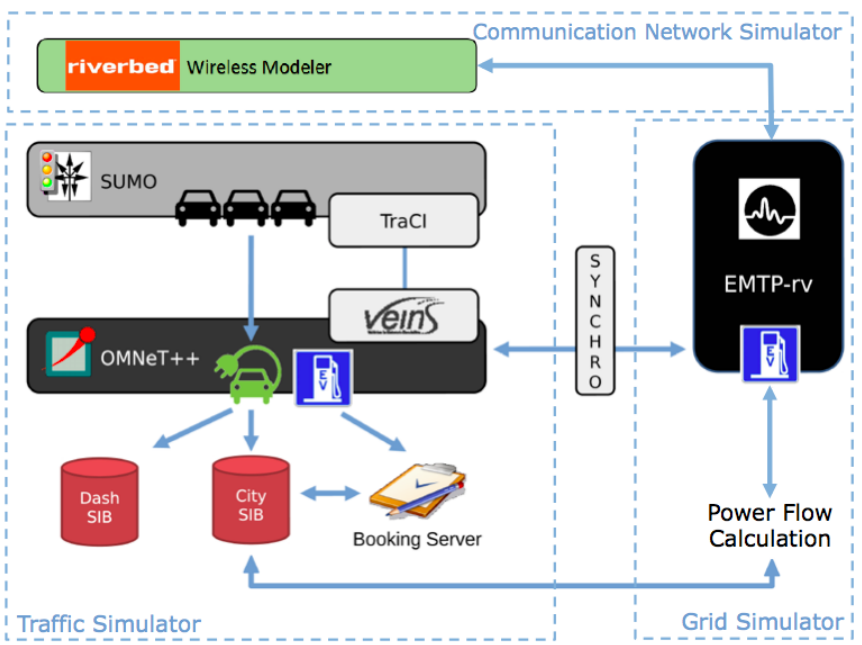

Fig. 13 - Block scheme of the co-simulation tool for traffic and power grid simulator enabling the assessment of e-mobility impact on the grid. The dash Semantic Information Broker (SIB) stores EV data and the city SIB stores reservation related information (adapted from [61])

In order to provide an illustrative application of this lastmentioned feature, Fig. 14 shows the locations of parking lots with EVSEs in Bologna. We focus here on two $15 \mathrm{kV}$ feeders fed by 132/15 kV substation SB_A (indicated in red in Fig. 14). To these feeders, the EVSE clusters of four parking lots are connected (EVSE_1 and EVSE_2 to feeder 1, EVSE_3 and EVSE_4 to feeder 2 respectively). Each cluster is composed by ten 50-kW charging units. Each of the feeders is equipped with an automatic control system that can reduce the charging power of each EVSE cluster to avoid network congestions.

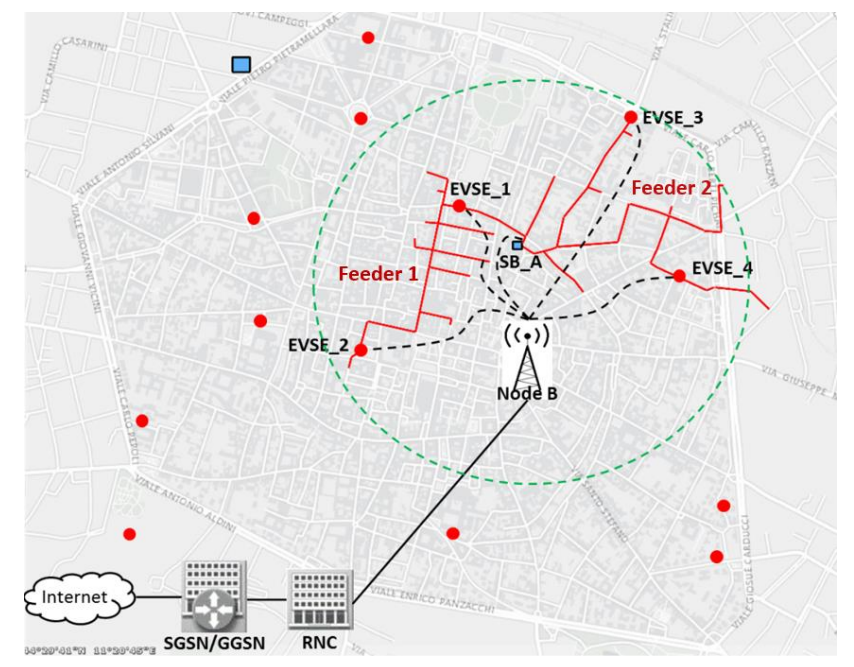

Fig. 14. Top view of the map of Bologna with the indication of parking lots with charging stations (red dots), of HV/MV substations (blue rectangles), the analyzed two $15 \mathrm{kV}$ feeders and the model of the UMTS communication network (dotted black lines represent wireless channels, solid black lines represent wired channel). The green circle indicates the estimated coverage areas of the Node B antenna (adapted from [61]).

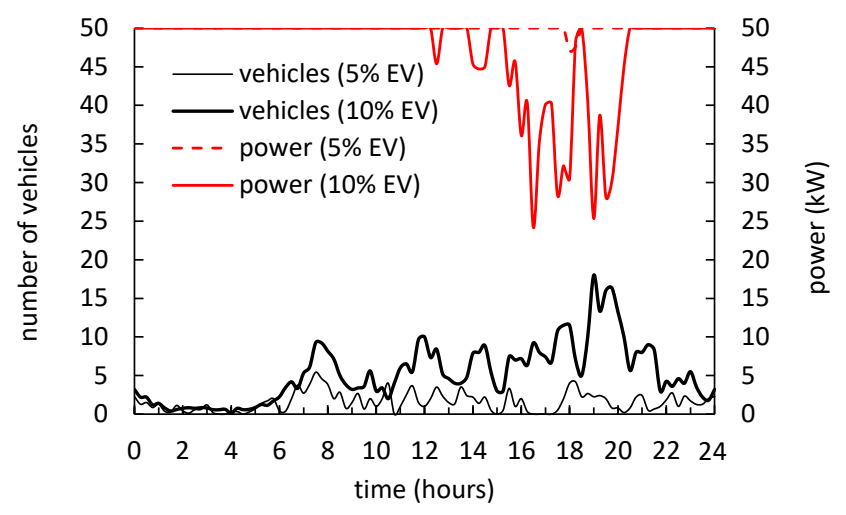

a)

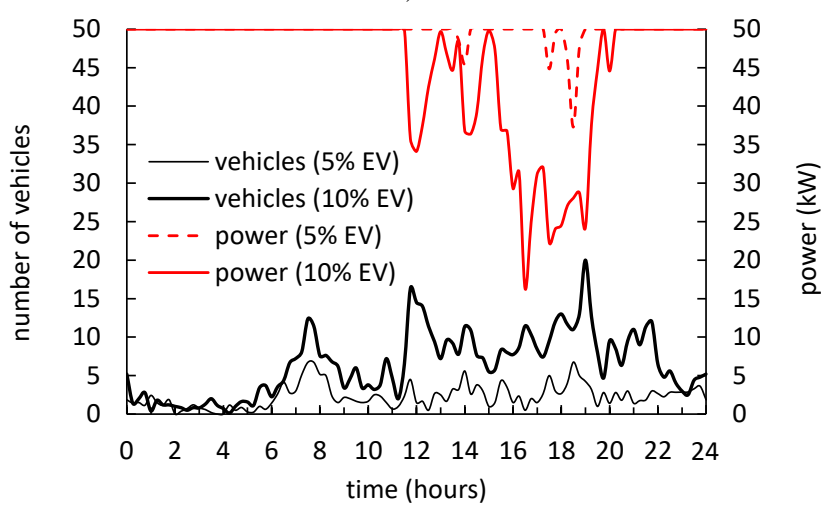

b)

Fig. 15 - Number of the recharging vehicles and power consumptions of EVSE in the 24 hours: a) feeder 1 ; b) feeder 2

In the mobility simulator, a scenario of 10,000 different routes generated according a predefined traffic rate is considered. The simulation of the power network considers also the presence of the usual average electric load profile that includes also residential uncontrolled EV charging. Additional details are reported in [61]. Fig. 15 shows the number of EVs connected to the EVSE clusters of both feeder 1 and feeder 2, for two different percentages of plug-in EVs in the traffic flow (namely, 5\% and 10\%). Further, Fig. 15 shows the maximum power available at each EVSE during the day. In all the periods when the maximum power is lower than $50 \mathrm{~kW}$, the already described MAS reduces the maximum power available for the EVs charging in order to counteract congestions in the power feeder. It can be observed that the parking lots supplied by feeder 1 tend to be less preferred by drivers compared those supplied by feeder 2 , due to the parking lot closeness to the avenues surrounding the downtown Bologna area. Whilst in the morning, e.g. around $8 \mathrm{AM}$, the distribution grid succeeds to handle the charging demand, in the evening the maximum power available for each EVSE is significantly reduced.

As a complement to the co-simulation platform, a set of route planner and recharging reservation services, hosted by the semantic platform integrated with the co-simulation platform, have been also developed in order to investigate and overcome some of the current well-known obstacles to the eMobility penetration, such as range anxiety and recharging time $[64,65]$. Procedures for the participation of aggregators of EV charging stations in the electricity market have been deliberately disregarded so far: the developed simulator can be however 
successfully used also for the analysis of the interface with the electricity market environment.

The above contribution is the outcome of multiannual incremental research with the cooperation of academic institutions and complementary industrial stakeholders like electricity distribution companies (ENEL), infrastructure and platform specialists (NOKIA Research Center, SIEMENS Research and Indra), car manufacturers research labs (CRF) and semiconductor companies (STMicroelectronics and Infineon) under the umbrella of the European Research agenda.

\section{SUSTAINABLE DistrictS AND URBAN ENVIRONMENTS: RESEARCH AT THE UNIVERSITY OF BOLOGNA}

\section{A. Historic Masonry Building and Environmental Actions}

Historic masonry buildings, trademark of many cities and villages, will only survive if preserved as living places. Hence, a deep understanding of their deterioration processes caused by the environment is fundamental to effectively preserve them. To gain information about such deterioration processes, continuous monitoring systems involving ICT are often used. However, most of the times, the installed sensors acquire climate parameters and the data analysis is performed just via basic models, so that the real effect of environmental actions on the structure is unaccounted for. Indeed, environmental actions, such as heat, moisture and salt transport combined with salt crystallization strongly influence the durability of historic building materials. In particular, salt crystallization is one of the major elements contributing to the environmental degradation of historic masonry and its importance is expected to increase due to the global climate change and pollution.

Although there is a vast literature on modeling and simulation of environmental degradation of porous building materials (see for example [66-68]), there is still need for a comprehensive and robust numerical framework for simulation and analysis of historic masonry buildings under combined mechanical and environmental actions at the engineering scale.

With reference to Fig. 1, we are here focusing the attention on the Process area where monitored data are processed through advanced simulation tools (Simulation phase in Fig. 2) aiming at predicting the deterioration of the buildings, fundamental step to provide appropriate preventive actions.

In this context, a novel coupled multiphase model for Hygro-Thermal-Chemical (HTC) analysis of masonry structures has been developed [69-71]. In the model, thermal effects are fully considered and a suitable modeling of the crystallization/dissolution and hydration/dehydration processes allows considering salts with hydrous and anhydrous crystals. The HTC model validation has been performed by successfully simulating the results of an extensive experimental campaign involving both lab experiments on drying sandstone samples and fired-clay brick masonry walls exposed to weather conditions, see Fig. 16. In addition to this, in order to effectively predict the risk of mechanical damage, a numerical homogenization procedure has been developed [70]. Such a procedure is based on the real 3D micro geometry of the porous material coming from X-ray Micro Computed Tomography images: starting from the HTC model results, it allows evaluating the mechanical effects of salt crystallization occurring at the macro-scale. Finally, in the same framework and with the aim of understanding the effects of deterioration processes caused by the environment at the scale of the building, a numerical multi-scale approach able to simulate the response of large-scale masonry walls has been developed [71]. Two scales of representation, sketched in Fig. 17, are considered within an iterative solver: a discrete model accounting for brick-by-brick interaction (local scale) and a finite element mesh (global scale) where each element accounts for the response of a generic pattern of bricks.

By taking into account the coupled HTC effects together with a new numerical homogenization procedure for the evaluation of the mechanical effects of salt crystallization and the multi-scale framework, new predictive tools were developed that pave the way for an effective analysis of historic buildings subjected to environmental actions. These tools could be used by conservation professionals not only to assess the current status of a given structure, but also to predict future scenarios, thus opening new opportunities for cultural-heritage smart-management.

It is worth noting that often, due to the absence of detailed information concerning the historic building, assumptions in the computational model are needed. In order to overcome the uncertainties deriving from that, the integration of sensor data from appropriate smart monitoring systems involving ICT into the computational model are worth of further investigation. These activities were carried out within the international research projects SMooHS [72] for the smart monitoring of historic structures, KISADAMA [73] aimed at developing an integrated approach for modeling and analysis of the environmental decay of historic masonry structures, and 3ENCULT [74] aimed at linking conservation of historic buildings and climate protection. These research projects are highly interdisciplinary and involve universities, conservation/technical experts, industry partners, and local public bodies. More details about the projects, the partners involved and their roles can be found in [72-74].

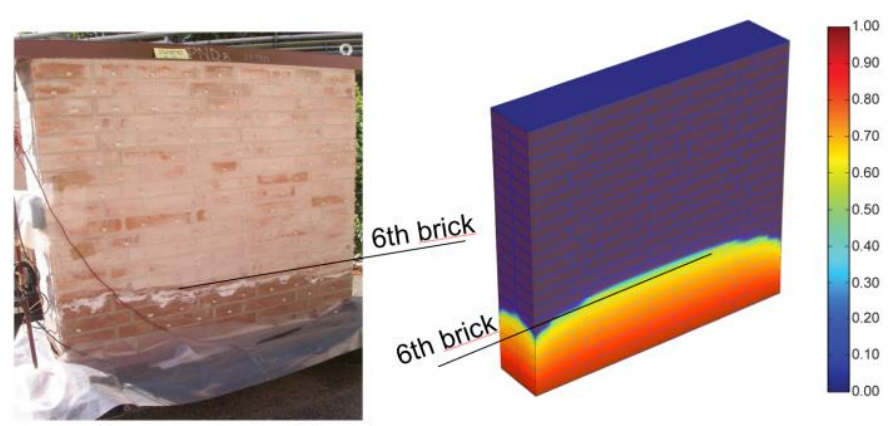

Fig. 16. Salt loaded masonry wall after 1 month: comparison between the experimental campaign and the simulated water saturation degree (adapted from [68]). 


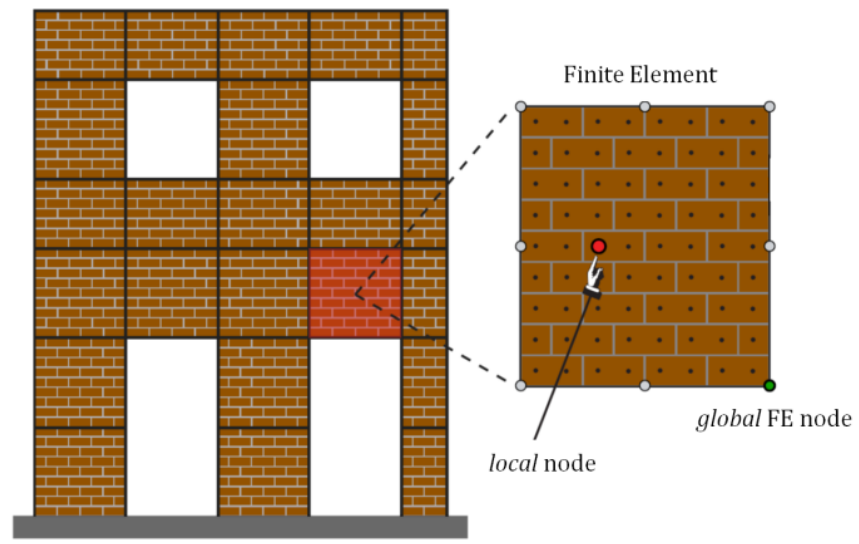

Fig. 17. Sketch of the multi-scale approach for the analysis of large-scale masonry walls (adapted from [71]).

\section{B. SMART WATERTECH - Smart Community for the Development and the Application of Monitoring Technologies and Control Systems applied to Integrated Water Service}

With the adoption of Directive 2000/60/EC (WFD), the implementation of adequate water management solutions is increasingly perceived as an absolute priority in Europe, with the aim to counteract the constantly increasing water demand and the need for environmental protection [75-77].

As a matter of fact, the origin of the SMART WATERTECH ${ }^{3}$ project comes from the awareness that the growing need of water, imposed by the improvement of living conditions, agricultural development and industrialization, is increasingly difficult to satisfy with the current water resources [78]. Furthermore, the already critical situation today is likely to deteriorate as a result of climatic change: the predictions of climate scientists, in fact, indicate for the Mediterranean area forthcoming conditions of greater aridity and more irregular precipitation [79]. Within this context, the project is aimed at the identification of tools and strategies that enable not only to maintain an adequate level of security of water supply and service for drinking, irrigation and industrial uses, but also an efficient and economical monitoring of water systems, with specific reference also to the treatment of water and wastewater [80-85].

With reference to the Smart City functional planning and operation scheme depicted in Fig. 2, SMART WATERTECH project considers innovative measures and tools that can be used both in the monitoring phase and in planning and operation activities. To pursue these objectives, the project develops new sensors and systems characterized by low costs and high reliability (based on radar and optoelectronic technology) and integrated systems for the collection and presentation of data (e.g., Decision Support Systems for planning and optimization of network parameters, algorithms for the pre-localization of water losses, data fusion algorithms for the integration of distributed optical sensors and Ground Penetrating Radar GPR- for high resolution monitoring).

Referring to the three pillars highlighted in Fig. 18 (i.e., water supply, sewer and irrigation systems) the above technologies, algorithms and procedures are optimized for the achievement of the following objectives:

- pervasive monitoring of water consumption in water systems and water losses detection; the implementation of an AMR (automatic meter reading) network enables to obtain a detailed knowledge of consumption, detect anomalies and generate alarms, develop advanced models for the simulation of water balances and predictive consumption models and optimal management of water distribution networks. Depending on the technology applied and finalities pursued AMR can provide (near) real time information offering new monitoring opportunities for both water suppliers and users [84].

- Water quality and quantity monitoring; the development of an efficient quali-quantitative monitoring network of water supply system allows, through integration with climatological and hydrological information, to archive the data relating to the various parameters and provide input elements for a planning and management model of water resources, able to generate scenarios and strategies for interventions at different time scales (short and medium / long term).

- Precision farming; the technology of wireless sensor networks (WSNs) enables large-scale monitoring of the physical parameters that administrate agricultural production processes, thus supporting precision irrigation techniques, services for environment preservation and pollutant monitoring.

The available scientific literature reports several applications of Automatic Meter Reading (AMR) to both urban water supplies and irrigation systems. For instance, AMR techniques have been widely applied for the detection of water losses in urban water distribution (e.g. [80], [81]), for the reduction of household water use (e.g. $[78,82]$ ) and for the optimization of network operation (e.g. $[81,83,85])$. However, the Smart Watertech project represents a first attempt to take advantage of AMR in order to integrate the manifold issues of water service in a comprehensive and holistic perspective, which envisions the different and frequently competitive water uses of a Smart Community as components of a unitary framework. In this view, the project identifies strategies to preserve a satisfactory level of security of water supply and service for drinking, irrigation and industrial use, while protecting the quality of water bodies.

This project involves 16 different partners (Universities, Water Utilities, Temporary Association of Companies and National Research Council). It represents a first attempt to systematize and apply knowledge, experience and technological solutions to some cases well away from the problems of water management. This is accomplished through a multiple-use approach to water, in order to achieve a higher level of added value in terms of economic, social and environmental sustainability.

\footnotetext{
${ }^{3}$ Smart Community for the Development and the Application of Monitoring Technologies and Control Systems applied to Integrated Water Service
} 


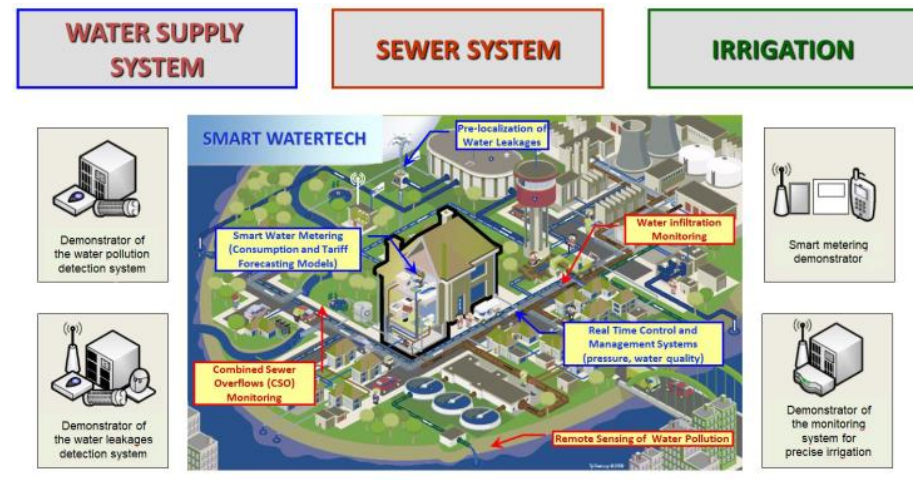

Fig. 18. Contexts and finalities of the SMART WATERTECH project

\section{The intelligent pole network within the Fondazione Alma Mater and successive Smart City implementation}

In the framework of the PEGASUS project (2009-2012) [86], funded by the Italian Ministry for Economic Development, the research group at the Wireless Communication Laboratory (Wilab-University of Bologna) realized a smart-lighting testbed at the premises of Fondazione Alma Mater, where a network of smart, remotely controlled, light poles was deployed, also capable of providing additional services in the Smart City perspective. This activity, aimed at showing the feasibility of a smart-lighting infrastructure based on wireless communication technologies, refers to the Infrastructures box of Fig. 1 as well as to the test bed phase highlighted in Fig. 2.

In particular, eight LED light poles, located in the park of the historic building Villa Gandolfi Pallavicini (Bologna), shown in Fig. 19, have been equipped with IEEE 802.15.4 short-range communication interfaces [87], which established a wireless mesh network among them. One of the poles was also capable of long-range communications through a cellular interface, to allow proper connection with a remote-control center. Full wireless control overcame the need for a fixed communication infrastructure, allowing the remote dimming of each light fixture independently of the others as well as the monitoring of their operating conditions through individual telemetering (e.g., power consumption and temperature) and telediagnostic. All the poles also provided Wi-Fi coverage to nearby users, thus enabling Internet connectivity, infotainment and touristoriented services.

The testbed was highly innovative with respect to the state of the art of smart-lighting infrastructures based on power-line communications (PLCs) [88]. The power-line technology for light poles networking is critical, for two main reasons:

- The presence of grid-generated disturbances, which could deeply affect the communication reliability and the maximum obtainable bit rate. In particular, PLCs are very vulnerable to switching power sources and relays, as well as induction motors.

- The presence of transformers between the medium-voltage and low-voltage grids. Here, an additional PLC equipment could be required in order to allow the PLC signals traversing the transformers.

Wireless technologies completely overcome such issues, as the communication and electrical power infrastructures are completely decoupled.

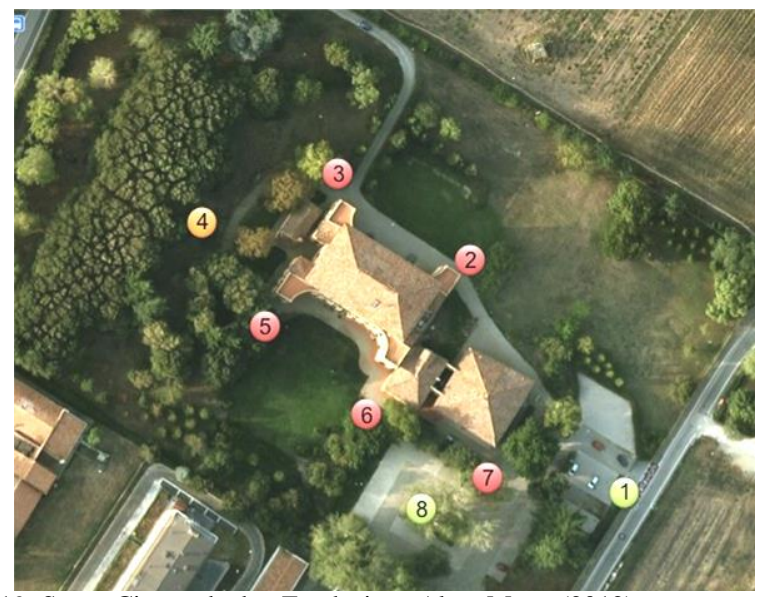

Fig. 19: Smart City testbed at Fondazione Alma Mater (2012).

The deep expertise gained from the deployment and management of such testbed led to the creation of a start-up, Wi4B, which is now technological partner of some of the most important players in the smart-city scenario, and to a large-scale implementation of the smart lighting technology in the Italian city of Montechiarugolo. Here, the whole public lighting infrastructure, about 3000 luminaries in a 211 square kilometers area, has been enhanced so as to accommodate LED lamps, along with the circuitry for their dimming, and IEEE 802.15.4 communication interfaces, which operate in the $2.4 \mathrm{GHz}$ band with a transmission power of $20 \mathrm{dBm}$. More, the intelligent poles are envisaged to host the future $5 \mathrm{G}$ base stations in the context of a dense, urban, mobile radio network.

Thanks to the wireless network, the light intensity of each street lamp can be remotely controlled and programmed by means of the fully integrated wireless network, thus obtaining high efficiency in the service provision and real-time fault detection.

The combined effect of LED lamps and wireless network control led to a significant energy consumption reduction, up to $-76 \%$ in a year (2014). However, the benefits of such technology are not limited to economic aspects. A relevant consequent effect is the availability of a capillary wireless network, which reaches every location where a smart light pole is present. This enables the collection of data and the provision of new services, concerning, for instance waste management, air quality monitoring, vehicular traffic monitoring and structural health monitoring.

Apart from technical aspects, mainly concerning the networking and management of thousands of streetlights, the most important lesson learned from the above-described activity is that large-scale implementations of smart lighting infrastructures based on wireless communication technologies are not only feasible but also highly advisable, as they allow easy deployments, significant money savings and provide the backbone for further smart services. 


\section{Smart and Sustainable Approach for Optimization /Renovation of the Built Environment}

The development and the adoption of systematic assessment strategies and criteria, able to predict or address the main impacts of the interventions at district scale (performance efficiency, urban quality and environmental sustainability) (Fig. 20) is a great challenge. Recently, particular attention has been devoted by the Operations Research group of the University of Bologna to the development of quantitative optimization methodologies (see e.g., [89, 90]). A quick and effective detection of the propensity of each element composing the district (from buildings to grids) to be improved can allow scheduling the envisaged actions (Fig. 1 - Processes), being aware of the potential consequent impacts in terms of energy efficiency, costs and achievable comfort level. To measure the "propensity of improvement factor" a conceptual framework has been developed through the definition scenario modeling (Fig. 20) based on indicators, which take into consideration technical, financial and social aspects: energy demand reduction and more efficient energy systems, resource availability, cost-reduction for intervention and maintenance, integration, regulations, social impacts, etc.

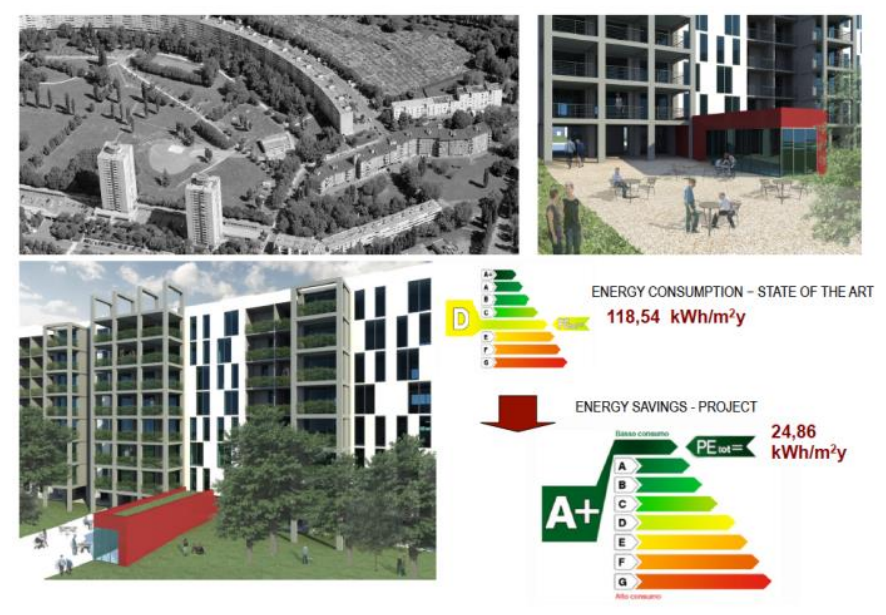

Fig. 20. Energy demand reduction. Scenario modeling.

The activity of RIGERS project ${ }^{4}$ [91] (led by ICIE $^{5}$, with participation of the University of Bologna), based on the integrated design strategy (Fig. 21) develops an integrated system to regenerate buildings and optimally design grids with a multi-objective approach (energy, environmental, functional, seismic) that uses ICT as an instrument to provide a response to the city's tangible needs [92]. Different disciplines are involved in this project (technology for architecture, physics, ICT, finance, civil engineering, electrical engineering, etc.) with the aim of facing an ambitious challenge: increasing the well-being and quality of life of citizens according to the Smart City paradigm (Fig. 1). The Interoperable Cooperative Platform for the Sustainable City implementation can effectively acquire, contain and manage data regarding the consistence, function and consumption of buildings (aggregated users) and grids,

\footnotetext{
4 "City Regeneration: Smart Buildings and Grids" - National Smart Cities Call - Industrial research, experimental development and training project, funded by the European structural funds - National Operative Programme (PON) Research and competitiveness.
}

capable of cooperating - through appropriate adapters - with other urban IT systems already being used by the various public administrations.

The scientific problem addressed by this project is very broad and covers the energy efficiency and security of buildings, industries and networks from an environmental sustainability point of view. With reference to the state of the art, its resolution includes the need to innovate a significant number of research fields including those that give particular importance to sustainable energy systems, seismic safety, new sustainable technologies, decision-making support systems and semantic interoperability.

The decision-making support system is based on a multicriteria analysis of different data sets following the integrated design approach (Fig. 21) [93]. Such an approach is aimed at identifying resilient scenario for urbanization renovation of existing buildings and districts, as well as at framing effective refurbishment design criteria at district scale, based on a LCA (Life Cycle Assessment) vision [94]. It also combines high performance in energy efficiency and sustainable solutions and technologies with customer-oriented strategies in order to ensure the gains completely fit with the users' expectations and requirements.

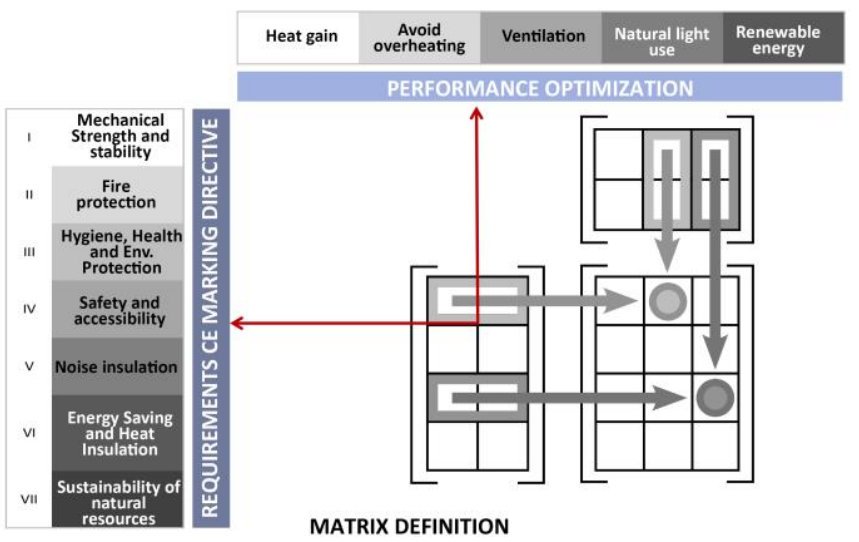

Fig. 21. Integrated design steps and matrix definition

The implementation of energy-efficiency improvements in all key-sectors requires the support and participation of the final energy consumer [95]. Behavior and local cultural factors can drive basic energy-use practices: end-users' involvement is based on the consumers' knowledge on energy issues and on their awareness on the possible energy efficiency improvement and their understanding of the costs and benefits involved in the different options.

There is a close relationship between behaviors and infrastructure [95]: energy infrastructure (e.g. smart grids, heating systems, roads and vehicles) plays a very active role in what people consider 'a normal way of life', but the interaction with new energy technologies is far from straightforward. The possible solutions consist in a combination of technical and social measures, through the adoption of user-friendly energy

\footnotetext{
5 ICIE stands for the Italian translation of Cooperative Institute for Innovation, Applied Research and Technology Transfer.
} 
efficiency systems that could facilitate the use by tenants and increase their environmental and energy awareness.

The introduction of public participation strategies and user's awareness in the design process, as well as of design tools and support measure for users so to improve a better relationship between user and technological system, can support more functional and contextualized choices about the technologies employed (Fig. 2). This integrated approach supports energy access strategies in the residential sector, and especially in Social Housing, which require an effective use of energy with the minimum purpose of economic resources, but also in some particular contexts, such as historic city centers in which technological integration and users' engagement in the regeneration process is fundamental.

The participation strategy to boost users' awareness is the focus of the on-going ROCK project, as a driver of sustainable growth - 2017-2020, led by Municipality of Bologna with the strong support of the University of Bologna, core-partner of the consortium [96]. Historic city centers are considered as extraordinary laboratories to demonstrate how Cultural Heritage $(\mathrm{CH})$ can represent a unique and powerful engine of regeneration, sustainable development and economic growth for the whole city. ROCK develops and applies an innovative circular systemic approach to connect different actors, sites of $\mathrm{CH}$ value and systems, at the European level as well as at a local one. It is based on a circular model approach in which a multiple innovation process (technical+organizational+institutional solution and changes) is capable to transform underused $\mathrm{CH}$ into new resource for the city as a whole, accelerating transition towards sustainable city growth.

By means of innovative site-data collection, mentoring, integration of smart technologies in historic context [97], ROCK is going to produce an appealing narrative of a novel model for $\mathrm{CH}$-driven and green-oriented city-center growth. At local level, this is expected to increase sense of ownership in the process of heritage adaptive reuse and promotion, with an inclusive approach for the well-being of all communities.

\section{CONCLUSIVE REMARKS}

There is general consensus that the Smart City paradigm represents the most promising approach to tackle the challenges posed by modern urban areas, whose population is expected to double by 2050. On the other hand, rigorously speaking, there is no single generally acceptable definition for a Smart City. All the available ones have however one feature in common: the multidimensional and multidisciplinary nature of what a Smart City represents.

This paper was aimed at supporting such a concept by making reference to some major research projects carried out by the Authors at the University of Bologna, in most cases within the framework of EU research programs, thanks to cooperation of a number of major players, other universities/institutions, the Bologna Municipality, the Emilia Romagna Region, and a few SMEs. To accomplish that, we have made reference to a vision of the Smart City paradigm restrained to the Engineering/Computer Science area with the help of a functional diagram of the Planning and Operation of Smart City processes as a function of citizens' active participation.

Three main areas of research activity are identified in line with the Smart City EU vision: i) Integrated infrastructures and processes, ii) Sustainable urban mobility, and iii) Sustainable districts and urban environments.

All the research projects described in the paper support the concept that effective implementation of the Smart City paradigm requires multi-disciplinary efforts. The number of disciplines involved can vary from case to case, as well as the nature of the models and algorithms used; this applies also to the data processing and optimization techniques, as it can be inferred by the illustrated matter.

The following three main lessons learned can be identified thanks to the activity carried out.

1. Few research areas other than Smart Cities require a close, frequent cooperation among researchers with different, complementary interests. The case of emobility, just to name one of the most significant examples provided in the paper, calls for technical skills in the areas of ICT systems, electric power networks/smart grids, electric vehicles, storage systems, and computer co-simulation tools for the integrated representation of systems belongings to heterogeneous domains.

2. Academics with different scientific background not only need to cooperate with each other and with industrial players more than for any other technical challenge, but they also need to interact and cooperate with local municipality governances and regional communities.

3. Although deliberately disregarded in this paper focused on technical issues, the development of relevant standards and business models is of utmost importance.

\section{ACKNOWLEDGMENT}

Bologna Municipality, Aster, UniBo ARIC and Fondazione Alma Mater and all players, companies and SMEs involved in the illustrated research activities are warmly acknowledged for their fundamental role in pursuing the described projects. Special thanks are due to Ernesto Antonini, Alessandro Bazzi, Paolo Bonaretti, Saveria Olga Boulanger, Cristiana Bragalli, Federico Chesani, Alessio Domeneghetti, Giovanni Fini, Jacopo Gaspari, Marco Gavanelli, Valentina Gianfrate, Matteo Lepore, Barbara Mavì Masini, Lucia Mazzoni, Giulia Olivieri, Elisabetta Palumbo, Fabio Tossani for their fruitful cooperation.

\section{REFERENCES}

[1] C. Cassandras, "Smart Cities as Cyber-Physical Social Systems", Engineering 2, pp. 156-158, 2016.

[2] Jing Zeng, Laurence T. Yang, Man Lin, Huansheng Ningc, Jianhua Ma, "A survey: Cyber-physical-social systems and their system-level design methodology", Future Generation Computer Systems, Available online 17 August 2016.

[3] M. Batty, "The New Science of Cities", Cambridge, MA: The MIT Press, 2014.

[4] United Nations, Department of Economic and Social Affairs, Population Division, "World Urbanization Prospects: The 2014 Revision," (ST/ESA/SER.A/366), 2015. [Online]. Available: 
https://esa.un.org/unpd/wup/Publications/Files/WUP2014-Report.pdf.

[5] A. Gharaibeh, M.A. Salahuddin, S.J. Hussini, A. Khreishah, I. Khalil, M. Guizani, and A. Al-Fuqaha, "Smart Cities: A Survey on Data Management, Security, and Enabling Technologies", IEEE Communications Surveys \& Tutorials, vol. 19, no. 4, pp. 2456-2501, Fourth Quarter 2017

[6] R. Morello, S. C. Mukhopadhyay, Z. Liu, D. Slomovitz, and S. R. Samantaray, "Advances on Sensing Technologies for Smart Cities and Power Grids: A Review", IEEE Sensors Journal, vol. 17, no. 23, pp. 7596-7610, Dec. 1, 2017.

[7] A. Zanella, N. Bui, A. Castellani, L. Vangelista and M. Zorzi, "Internet of Things for Smart Cities", IEEE Internet of Things Journal, vol. 1, no. 1, pp. 22-32, February 2014.

[8] S. Helal, "IT Footprinting - Groundwork for Future Smart Cities," Computer, vol. 44, no. 6, pp. 30-31, June 2011.

[9] D. Mazza, D. Tarchi, and G. E. Corazza, "A unified urban mobile cloud computing offloading mechanism for Smart Cities," IEEE Commun. Mag., vol. 55, no. 3, pp. 30-37, March 2017.

[10] N. Abbas, Y. Zhang, A. Taherkordi and T. Skeie, "Mobile Edge Computing: A Survey," IEEE Internet of Things Journal, vol. 5, no. 1, pp. 450-465, Feb. 2018.

[11] Y. Mao, C. You, J. Zhang, K. Huang and K. B. Letaief, "A Survey on Mobile Edge Computing: The Communication Perspective," IEEE Communications Surveys \& Tutorials, vol. 19, no. 4, pp. 2322-2358, Fourth Quarter 2017

[12] H. T. Dinh, C. Lee, D. Niyato, and P. Wang, "A survey of mobile cloud computing: architecture, applications, and approaches," Wirel. Commun. Mob. Comput., vol. 13, no. 18, pp. 1587-1611, Dec. 2013

[13] Z. Pang, L. Sun, Z. Wang, E. Tian and S. Yang, "A Survey of Cloudlet Based Mobile Computing," 2015 International Conference on Cloud Computing and Big Data (CCBD), Shanghai, China, 2015, pp. 268-275.

[14] F. Bonomi, R. Milito, P. Natarajan, J. Zhu, "Fog computing: A platform for Internet of Things and analytics" in Big Data and Internet of Things: A Roadmap for Smart Environments, Cham, Switzerland:Springer, pp. 169-186, Mar. 2014.

[15] M. Chiang and T. Zhang, "Fog and IoT: An Overview of Research Opportunities," in IEEE Internet of Things Journal, vol. 3, no. 6, pp. 854864, Dec. 2016.

[16] D. Mazza, A. Pagès-Bernaus, D. Tarchi, A. A. Juan, and G. E. Corazza, "Supporting Mobile Cloud Computing in Smart Cities via Randomized Algorithms," IEEE Syst. J., accepted for publication, 2016.

[17] S. Barbarossa, S. Sardellitti, and P. Di Lorenzo, "Communicating while computing: Distributed mobile cloud computing over $5 \mathrm{G}$ heterogeneous networks," IEEE Signal Process. Mag., vol. 31, no. 6, pp. 45-55, Nov. 2014.

[18] X. Chen, "Decentralized computation offloading game for mobile cloud computing," IEEE Trans. Parallel Distrib. Syst., vol. 26, no. 4, pp. 974 983, April 12015.

[19] A. Checko, H. L. Christiansen, Y. Yan, L. Scolari, G. Kardaras, M. S. Berger, and L. Dittmann, "Cloud RAN for Mobile Networks-A Technology Overview," IEEE Commun. Surv. Tutorials, vol. 17, no. 1, pp. 405-426, Firstquarter 2015.

[20] D. Mazza, D. Tarchi, and G. E. Corazza, "A user-satisfaction based offloading technique for Smart City applications," in IEEE Global Commun. Conf., Austin, TX, USA, Dec. 2014, pp. 2783-2788.

[21] M. Milano, B. O’Sullivan, and M. Gavanelli, "Sustainable Policy Making: A Strategic Challenge for Artificial Intelligence," AI Mag., vol. 35, no. 3, pp. 22-35, 2014.

[22] M. Milano and M. Lombardi, "Strategic decision making on complex systems," Constraints, vol. 19, no. 2, pp. 174-185, 2014.

[23] ePolicy project. http://www.epolicy-project.eu/.

[24] M. Gavanelli, M. Milano, S. Bragaglia, F. Chesani, E. Marengo, and P. Cagnoli, "Multi-Criteria Optimal Planning for Energy Policies in CLP," in CILC, 2014, pp. 54-68.

[25] M. Lombardi, M. Milano, and A. Bartolini, "Empirical decision model learning," Artif. Intell., vol. 244, pp. 343-367, 2017.

[26] A. Borghesi, M. Milano, M. Gavanelli, and T. Woods, "Simulation of Incentive Mechanisms for Renewable Energy Policies," in ECMS, 2013, pp. 32-38.

[27] P. Ahrweiler, M. Schilperoord, A. Pyka, and N. Gilbert, "Modelling research policy: Ex-ante evaluation of complex policy instruments," $J$. Artif. Soc. Soc. Simul., vol. 18, no. 4, 2015.

[28] I. Gupellil and K. Boukhalfa, "Social big data mining: A survey focused on opinion mining and sentiments analysis," in 12th International Symposium on Programming and Systems (ISPS), 2015, pp. 132-141.
[29] G. Cardone, A. Corradi, L. Foschini, and R. Ianniello, "ParticipAct: A Large-Scale Crowdsensing Platform," IEEE Trans. Emerg. Top. Comput., vol. 4, no. 1, pp. 21-32, Jan.-March 2016.

[30] B. Guo et al., "Mobile Crowd Sensing and Computing: The Review of an Emerging Human-Powered Sensing Paradigm," ACM Computing Surveys, vol. 48, no. 1, Article 7, pp. 1-31, August 2015.

[31] X. Hu, T. H. S. Chu, H. C. B. Chan, and V. C. M. Leung, "Vita: A Crowdsensing-Oriented Mobile Cyber-Physical System," IEEE Transactions on Emerging Topics in Computing, vol. 1, no. 1, pp. 148165, June 2013.

[32] I. Carreras, D. Miorandi, A. Tamilin, E. R. Ssebaggala, and N. Conci, "Matador: Mobile task detector for context-aware crowd-sensing campaigns," in PERCOM Workshops '13: Proceedings of the IEEE International Conference on Pervasive Computing and Communications Workshops, 2013, pp. 212-17.

[33] M.-R. Ra, B. Liu, T. La Porta, and R. Govindan, "Medusa: A Programming Framework for Crowd-Sensing Applications," in MobiSys '12: Proceedings of the 10th International Conference on Mobile Systems, Applications, and Services, 2012, pp. 337-350.

[34] Participact Project web site: http://participact.unibo.it

[35] S. Chessa, A. Corradi, L. Foschini, and M. Girolami, "Empowering mobile crowdsensing through social and ad hoc networking," IEEE Commun. Mag., vol. 54, no. 7, pp. 108-114, July 2016.

[36] S. Chessa, M. Girolami, L. Foschini, R. Ianniello, A. Corradi, and P. Bellavista, "Mobile crowd sensing management with the ParticipAct living lab," Pervasive and Mobile Computing, vol. 38, no. 1, pp. 200-214, 2017.

[37] M. Tang, S. Pongpaichet, R. Jain, "Research Challenges in Developing Multimedia Systems for Managing Emergency Situations," in ACM MM, 2016.

[38] H. Hu, Y. Wen, T.-S. Chua, X. Li, "Toward Scalable Systems for Big Data Analytics: A Technology Tutorial," IEEE Access, vol. 2, pp. 652687, 2014.

[39] I. Bartolini and M. Patella, "A General Framework for Real-Time Analysis of Massive Multimedia Streams," Multimedia Systems, pp. 1-16, Springer Berlin Heidelberg, ISSN 0942-4962, DOI: 10.1007/s00530-0170566-5, 2017.

[40] I. Bartolini and M. Patella, "Comparing Performances of Big Data Stream Processing Platforms with RAM ${ }^{3}$ S," in SEBD, 2017.

[41] M.M. Gaber, A. Zaslavsky, S. Krishnaswamy, "Mining Data Streams: A Review," ACM SIGMOD Record, vol. 34, no. 2, pp. 18-26, 2005.

[42] I. Bartolini, P. Ciaccia, and M. Patella, "Query processing issues in region-based image databases," Knowl. Inf. Syst., vol. 25, no. 2, pp. 389420, 2009.

[43] O. Andrisano, V. Tralli, and R. Verdone, "Millimeter waves for shortrange multimedia communication systems," Proc. IEEE, vol. 86, no. 7, pp. 1383-1401, July 1998.

[44] O. Andrisano, R. Verdone, and M. Nakagawa, "Intelligent transportation systems: the role of third generation mobile radio networks," IEEE Commun. Mag., vol. 38, no. 9, pp. 144-151, Sep. 2000.

[45] A. Bazzi, B. M. Masini, G. Pasolini, and P. Torreggiani, "Telecommunication systems enabling real time navigation," in IEEE Conf. on Intelligent Transportation Systems (ITSC), Sept 2010, pp. 10571064

[46] C. De Castro, C. Raffaelli, and O. Andrisano, "A dynamic hierarchical VANET architecture for named data networking applications," IEEE Int. Conf. Commun. (ICC), June 2015, pp. 3659-3665.

[47] A. Bazzi, B. M. Masini, A. Zanella, and G. Pasolini, "IEEE 802.11p for cellular offloading in vehicular sensor networks," Cотриt. Соттип., vol. 60, pp. 97-108, 2015.

[48] A. Bazzi, B. M. Masini, and G. Pasolini, "V2V and V2R for cellular resources saving in vehicular applications," in Wireless Communications and Networking Conference (WCNC), IEEE, Apr. 2012, pp. 3199 -3203.

[49] A. Bazzi, B. M. Masini, A. Zanella, and G. Pasolini, "Vehicle-to-vehicle and vehicle-to-roadside multi-hop communications for vehicular sensor networks: Simulations and field trial," in IEEE Inter. Conf. Comm. (ICC), June 2013, pp. 515-520.

[50] A. Bazzi, A. Zanella, B. M. Masini, and G. Pasolini, "A distributed algorithm for virtual traffic lights with IEEE 802.11p," in 2014 European Conf. on Networks and Communications (EuCNC), June 2014, pp. 1-5.

[51] O. Andrisano, M. Dell'Acqua, G. Mazzini, R. Verdone and A. Zanella, "On the parameters optimization in handover algorithms," in 48th IEEE Vehicular Technology Conference (VTC 98), Ottawa, Ont., 1998, pp. 1400-1404 vol.2.

[52] A. Toppan, A. Bazzi, P. Toppan, B. M. Masini, and O. Andrisano, 
"Architecture of a simulation platform for the smart navigation service investigation," in IEEE Int. Conf. on Wireless and Mobile Computing, Networking and Communications (WiMob), Oct. 2010, pp. 548-554.

[53] VISSIM. http://vision-traffic.ptvgroup.com/en-us/products/ptv-vissim/

[54] A. Bazzi, C. Gambetti, and G. Pasolini, "SHINE: Simulation platform for heterogeneous interworking networks," in IEEE Int. Conf. on Comm. (ICC), Istanbul, Turkey, Jun. 2006, pp. 5534-5539.

[55] F. Zabini, A. Bazzi, B. M. Masini and R. Verdone, "Optimal Performance Versus Fairness Tradeoff for Resource Allocation in Wireless Systems," in IEEE Transactions on Wireless Communications, vol. 16, no. 4, pp. 2587-2600, April 2017.

[56] F. Zabini and A. Conti, "Ginibre sampling and signal reconstruction," IEEE International Symposium on Information Theory (ISIT), Barcelona, 2016.

[57] J. A. P. Lopes, F. J. Soares, and P. M. R. Almeida, "Integration of Electric Vehicles in the Electric Power System," Proc. IEEE, vol. 99, no. 1, pp. 168-183, Jan. 2011.

[58] M. D. Galus, R. A. Waraich, F. Noembrini, K. Steurs, G. Georges, K. Boulouchos, K. W. Axhausen, and G. Andersson, "Integrating Power Systems, Transport Systems and Vehicle Technology for Electric Mobility Impact Assessment and Efficient Control," IEEE Trans. Smart Grid, vol. 3, no. 2, pp. 934-949, June 2012.

[59] E. L. Karfopoulos and N. D. Hatziargyriou, "A Multi-Agent System for Controlled Charging of a Large Population of Electric Vehicles," IEEE Trans. Power Syst., vol. 28, no. 2, pp. 1196-1204, May 2013.

[60] W. Wei, L. Wu, J. Wang, and S. Mei, "Expansion Planning of Urban Electrified Transportation Networks: A Mixed Integer Convex Programming Approach," IEEE Trans. Transp. Electrif., vol. 3, no. 1, pp. 210-224, March 2017.

[61] L. Bedogni, L. Bononi, A. Borghetti, R. Bottura, A. D’Elia, M. Di Felice, F. Montori, F. Napolitano, C. A. Nucci, T. Salmon Cinotti, and F. Viola, "An integrated traffic and power grid simulator enabling the assessment of e-mobility impact on the grid: a tool for the implementation of the smart grid/city concept," J. Eng. Sci. Eng. Innov. Acad. Tech. Sci. Rom., vol. 1, no. 1,2016

[62] L. Bedogni, L. Bononi, M. Di Felice, A. D’Elia, R. Mock, F. Morandi, S. Rondelli, T. Salmon Cinotti, and F. Vergari, "An Integrated Simulation Framework to Model Electric Vehicles Operations and Services," IEEE Trans. Veh. Technol., vol. 65, no. 8, pp. 5900-5917, Aug. 2016. See also www.artemis-ioe.eu

[63] L. Roffia, F. Morandi, J. Kiljander, A. D’Elia, F. Vergari, F. Viola, L. Bononi, and T. Salmon Cinotti, "A Semantic Publish-Subscribe Architecture for the Internet of Things," IEEE Internet Things J., vol. 3, no. 6, pp. 1274-1296, 2016. See also https://artemis-ia.eu/project/4sofia.html

[64] A. D’Elia, F. Viola, F. Montori, M. Di Felice, L. Bedogni, L. Bononi, A. Borghetti, P. Azzoni, P. Bellavista, D. Tarchi, R. Mock, and T. Salmon Cinotti, "Impact of Interdisciplinary Research on Planning, Running, and Managing Electromobility as a Smart Grid Extension," IEEE Access, vol. 3, pp. 2281-2305, 2015.

[65] L. Bedogni, L. Bononi, M. Di Felice, A. D’Elia, and T. Salmon Cinotti, "A Route Planner Service with Recharging Reservation: Electric Itinerary with a Click," IEEE Intell. Transp. Syst. Mag., vol. 8, no. 3, pp. 75-84, Fall 2016.

[66] M. Koniorczyk, D. Gawin, "Modelling of salt crystallization in building materials with microstructure - poromechanical approach", Constr. Build. Mater., vol. 36, pp. 860-873, 2012.

[67] H. Derluyn, P. Moonen, J. Carmeliet, "Deformation and damage due to drying-induced salt crystallization in porous limestone", Journal of the Mechanics and Physics of Solids, vol.63, pp. 242-255, 2014.

[68] G. Castellazzi, C. Colla, S. de Miranda, G. Formica, E. Gabrielli, L. Molari, and F. Ubertini, "A coupled multiphase model for hygrothermal analysis of masonry structures and prediction of stress induced by salt crystallization," Constr. Build. Mater., vol. 41, pp. 717-731, 2013.

[69] G. Castellazzi, S. de Miranda, L. Grementieri, L. Molari, and F. Ubertini, "Multiphase model for hygrothermal analysis of porous media with salt crystallization and hydration," Mater. Struct., vol. 49, no. 3, pp. 1039$1063,2016$.

[70] L. Grementieri, F. Daghia, L. Molari, G. Castellazzi, H. Derluyn, V. Cnudde, S. de Miranda, "A multi-scale approach for the analysis of the mechanical effects of salt crystallisation in porous media", International Journal of Solids and Structures, vol. 126-127, pp. 225-239, 2017.

[71] G. Castellazzi, S. de Miranda, G. Formica, L. Molari, and F. Ubertini, "Coupled hygro-mechanical multiscale analysis of masonry walls," Eng.
Struct., vol. 84, pp. 266-278, 2015.

[72] SMooHS - Smart monitoring of historic structures (www.smoohs.eu), FP7 ENV.2007, 2008-2011.

[73] KISADAMA - Kinetics of salt crystallization and mechanical damage in historic masonry (www.kisadama.eu), JPI - JOINT HERITAGE EUROPEAN PROGRAMME, 2013-2016.

[74] 3ENCULT - Efficient energy for EU cultural heritage (www.3encult.eu), FP7 ENV.2010, 2010-2014.

[75] D. Brooks, "An operational definition of water demand management," Water Resour. Dev., vol. 22, no. 4, pp. 521-528, 2006.

[76] T. R. Gurung, R. A. Stewart, C. D. Beal, and A. K. Sharma, "Smart meter enabled informatics for economically efficient diversified water supply infrastructure planning," J. Clean. Prod., vol. 135, pp. 1023-1033, 2016.

[77] C. J. Van Leeuwen, S. H. A. Koop, and R. M. A. Sjerps, "City Blueprints: baseline assessments of water management and climate change in 45 cities," Environ. Dev. Sustain., vol. 18, no. 4, pp. 1113-1128, 2016.

[78] R. Cardell-Oliver, J. Wang, and H. Gigney, "Smart Meter Analytics to Pinpoint Opportunities for Reducing Household Water Use," J. Water Resour. Plan. Manag., no. 6, pp. 1-9, 2014.

[79] European Environment Agency (EEA), "Adapting to climate changeSOER 2010 thematic assessment," in The European Environment-State and Outlook Report; State of the environment Report No. 1/2010; EEA: Brussels, Belgium, 2010.

[80] T. Liserra, S. Artina, C. Bragalli, and C. Lenzi, "Water loss dynamic control by Automatic Meter Readings in water distribution network," in Integrating Water Systems, London: CRC Press Taylor \& Francis Group, 2009, pp. 71-77.

[81] D. Loureiro, C. Amado, A. Martins, D. Vitorino, A. Mamade, and S. T. Coelho, "Water distribution systems flow monitoring and anomalous event detection: A practical approach," Urban Water J., vol. 13, no. 3, pp. $242-252,2015$

[82] J. J. Harou, P. Garrone, A. E. Rizzoli, A. Maziotis, A. Castelletti, P. Fraternali, J. Novak, R. Wissmann-Alves, and P. A. Ceschi, "Smart metering, water pricing and social media to stimulate residential water efficiency: Opportunities for the SmartH2O project," 16th Conference on Water Distribution System Analysis, WDSA 2014 Procedia Eng., vol. 89, pp. 1037-1043, 2014.

[83] R. Ribeiro, D. Loureiro, J. Barateiro, J. R. Smith, M. Rebelo, P. Kossieris, P. Gerakopoulou, C. Makropoulos, P. Vieira, and L. Mansfield, "Framework for technical evaluation of decision support systems based on water smart metering: the iWIDGET case," 13th Computer Control for Water Industry Conference, CCWI 2015 Procedia Eng., vol. 119, no. 1, pp. $1348-1355,2015$.

[84] A. L. Sønderlund, J. R. Smith, C. J. Hutton, Z. Kapelan, and D. Savic, "Effectiveness of Smart Meter-Based Consumption Feedback in Curbing Household Water Use: Knowns and Unknowns," J. Water Resour. Plan. Manag., vol. 142, no. 12, p. 4016060, 2016.

[85] A. Fouial, I. García, C. Bragalli, A. Brath, N. Lamaddalena, and J. A. R. Diaz, "Optimal operation of pressurised irrigation distribution systems operating by gravity," Agric. Water Manag., vol. 184, no. C, pp. 77-85, 2017.

[86] Pegasus project https://www.metasystem.it/index.php/msy_ita_en/ content/view/full/ 35837

[87] Part 15.4: Wireless Medium Access Control (MAC) and Physical Layer (Phy) Specifications for Low-Rate Wireless Personal Area Networks (LR-WPANS), 2006. IEEE 802.15.4 Std.

[88] S. Galli, A. Scaglione and Z. Wang, "For the Grid and Through the Grid: The Role of Power Line Communications in the Smart Grid," Proceedings of the IEEE, vol. 99, no. 6, pp. 998-1027, June 2011.

[89] A. Bettinelli, A. Gordini, A. Laghi, T. Parriani, M. Pozzi, and D. Vigo, "Decision Support Systems for Energy Production Optimization and Network Design in District Heating Applications," in Real-World Decision Support Systems. Integrated Series in Information Systems, J. Papathanasiou, N. Ploskas, and I. Linden, Eds. Springer, 2016.

[90] C. Bordin, A. Gordini, and D. Vigo, "An optimization approach for district heating strategic network design," Eur. J. Oper. Res., vol. 252, no. 1, pp. 296-307, 2016.

[91] RIGERS, http://www.da.unibo.it/it/ricerca/Attivita-di-ricerca/rigers

[92] A. Boeri, E. Antonini, J. Gaspari, and D. Longo, Energy Design Strategies for Retrofitting. Methodology, Technologies and Applications. Southampton: WIT Press, 2015.

[93] A. Boeri, E. Antonini, and D. Longo, Edilizia abitativa ad alta densità. Strumenti di Analisi e Strategie di Rigenerazione: Il quartiere Pilastro a Bologna. Milano: Mondadori, 2013.

[94] M. Lotteau, P. Loubet, M. Pousse, E. Dufrasnes, and G. Sonnemann, 
"Critical review of life cycle assessment (LCA) for the built environment at the neighborhood scale," Build. Environ., vol. 93, pp. 165-178, 2015.

[95] European Environment Agency, "Achieving energy efficiency through behaviour change: what does it take?," 2013.

[96] Rock project. Regeneration and Optimisation of Cultural heritage in creative and Knowledge cities - Co-founded by EU - H2020-SC5-21 Cultural heritage. https://rockproject.eu

[97] E. Shove, "Beyond the ABC: Climate change policy and theories of social change," Environ. Plan. A, vol. 42, no. 6, pp. 1273-1285, 2010.

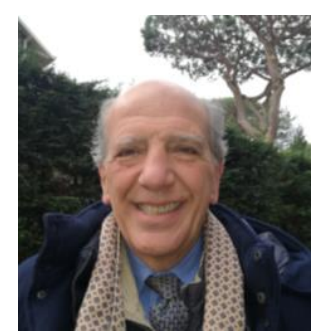

Oreste Andrisano (M'83) received the Dr.Ing. (cum laude) degree in electronics engineering from the University of Bologna, Bologna, Italy, in 1975. In 1975, he joined the University of Bologna, where he became a Professor of Electrical Engineering, in 1985. From 1993 to 2002, he was the Director of Centro di Studio per l'Informatica e i Sistemi di Telecomunicazioni, National Research Council. He founded the Wireless Communication Laboratory, WiLab, as a result of tight cooperation between the National Council of Research, University of Bologna, and Consorzio Nazionale Interuniversitario per le Telecomunicazioni (CNIT). He cofounded the CNIT, Naples, in 1994, and the Multimedia Communication Laboratory, in 2000. He has been the Laboratory's Director for three years, since its foundation (Labnet project). He has been the Coordinator of various research projects at the international and national levels in multimedia, intelligent transportation systems, and e-learning. $\mathrm{He}$ has been a Consultant for various industries, such as Siemens Mobile, Telecom Italia Mobile, and Alcatel Alenia Space. His research interests include digital signal processing, cellular systems, heterogeneous wireless networks, digital broadcasting, and infomobility. He was an Associate Editor of the IEEE Transactions on Communications for the topic "Modulation for fading channels" from 1996 to 2001. He is a member of the IEEE Communications Society, the IEEE Vehicular Technology Society, and the IEEE Communications Society Radio Communications Committee.

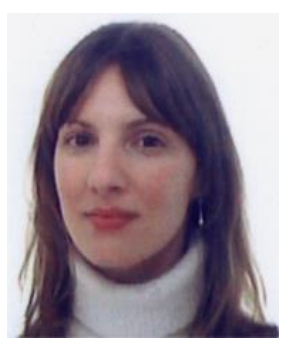

Ilaria Bartolini (M) received the Laurea degree in computer science (1997) and the $\mathrm{PhD}$ degree in electronic and computer engineering (2002) from the University of Bologna, where she has been an associate professor since 2014 . Her current research interests primarily concerns the effective and efficient management of big data and multimedia data collections, similarity and preference-based query processing, and collaborative filtering/advertising. She has been a visiting researcher at CWI (Amsterdam) and NJIT (Newark, NJ, U.S.A.), and a visiting professor at HKUST (Hong Kong, China).

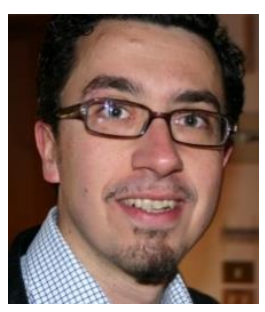

Paolo Bellavista (SM) graduated from the University of Bologna, Italy, where he received a Ph.D. degree in computer science engineering in 2001. He is now an associate professor at the University of Bologna, Italy. His research activities span from mobile agent-based middleware solutions and pervasive wireless computing to location/context-aware services and management of cloud systems. He serves on the Editorial Boards of IEEE T. on Network and Service Management, IEEE T. on Services Computing, Elsevier Pervasive Mobile Computing, and Springer Journal of Network and Systems Management.

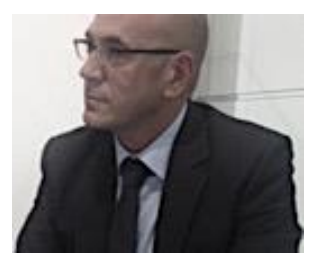

Andrea Boeri Full Professor of Technology for Architecture, Dean of the Department of Architecture. Member of the Ph.D. Committee of UNIBO-DA. Scientific director of the "OFF_line laboratory". Coordinator of the Chapter Emilia-Romagna for the Green Building Council -IT and of the national group for the Site Sustainability - LEED protocol. Coordinator of scientific research groups on sustainable renovation of the built environment and technological innovation for energy efficiency, smart and resilient cities to face the challenge of the climate issue.

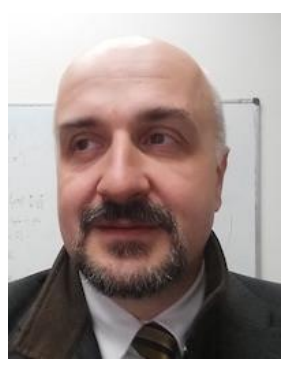

Luciano Bononi (MSC, Summa cum laude, 1997, Ph.D, 2001), Associate Professor of Computer Networks (11145), Internet of Things (81683), Wireless and Mobile System (77808) and Mobile Applications (66860) at the Department of Computer Science and Engineering (CSE) of the University of Bologna.

Co-author of more than 120 papers on the above topics, he is the founder and director of the Laboratory of Wireless Systems and Mobile Applications of the CSE Department.

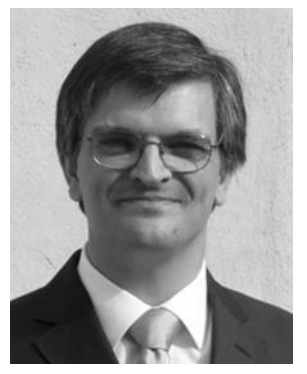

Alberto Borghetti (M'97-SM'03-F'15) was born in Cesena, Italy, in 1967. He graduated (with honors) in electrical engineering from the University of Bologna, Italy, in 1992. Since then he has been working with the power system group of the same University, where he is now Associate Professor. He is the author or coauthor of over 150 scientific papers published in peer-reviewed journals or presented at international conferences. He has served as keynote speaker, session chairman/moderator and member of the scientific committee at various international conferences in the field of power systems and lightning protection. He has served as Technical Program Committee chairperson of the 2010 30th Int. Conf. on Lightning Protection and co-chair of the 2016 Bologna CIGRE Colloquium on Lightning and Power systems. He is special reporter for the CIGRE 2018. In 2016, he was the 
recipient of the Int. Conf. on Lightning Protection Scientific Committee Award. From 2010 to 2017 he has served as an Editor of IEEE Trans. on Smart Grid. Currently, he is serving as an Editor of IEEE Trans. on Power Systems and as editorial board member of Electric Power Systems Research.

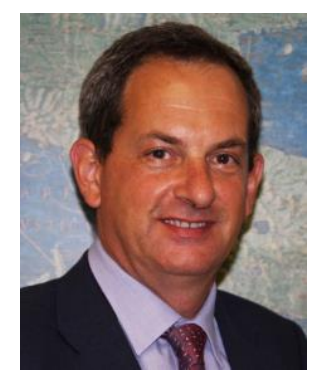

Armando Brath graduated with honors in Hydraulic Engineering from the University of Pisa in 1983 and earned his $\mathrm{PhD}$ in Hydraulic Engineering at the Politecnico of Milan in 1987. Since 1994 is Full professor of Hydraulic Engineering and Hydrology at the University of Bologna. Dean of the School of Civil Engineering from 1998 to 2007 and member of the Research Observatory of the University for two three-year-terms (20042010). Author of more than 250 scientific papers. For the past thirty years, served as consultant Professional Engineer for both public and private entities. From September 2015 is President of the Italian Hydrotechnical Association. He is member of the National Committee for Predicting and Preventing Major Risks in Italy, the connecting structure between the National Service of Civil Protection and the scientific community.

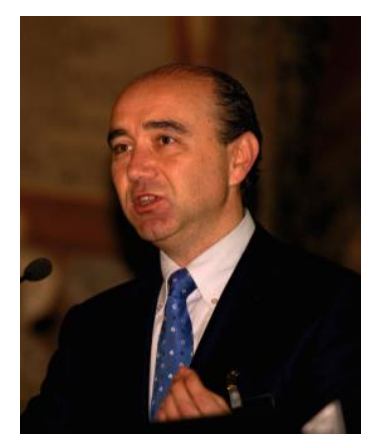

Giovanni Emanuele Corazza is a Full Professor and Member of the Board of Directors at the Alma Mater Studiorum-University of Bologna, President of the CINECA consortium for supercomputing, founder of the Marconi Institute for Creativity, President of the Scientific Committee of the Fondazione Guglielmo Marconi, Member of the Marconi Society Board of Directors, and Member of the Partnership Board of the 5G Infrastructure Association. He was Head of the Department of Electronics, Computer Science and Systems (DEIS) in the years 2009-2012, Chairman of the School for Telecommunications in the years 2000-2003, Chairman of the Advanced Satellite Mobile Systems Task Force (ASMS TF), Founder and Chairman of the Integral Satcom Initiative (ISI), a European Technology Platform devoted to Satellite Communications, Member of the Board of the 5G Infrastructure Association and Vice-Chairman of the NetWorld2020 European Technology Platform in the years 2013-2016. In the years 1997-2012, he has served as Editor for Communication Theory and Spread Spectrum for the IEEE Transactions on Communications. He is author of more than 300 papers, and received the Marconi International Fellowship Young Scientist Award in 1995, the IEEE 2009 Satellite Communications Distinguished Service Award, the 2013 Newcom\# Best Paper Award, the 2002 IEEE VTS Best System Paper Award, the Best Paper Award at IEEE ISSSTA'98, at IEEE ICT2001, and at ISWCS 2005. His research interests are in creativity and innovation, 5G systems, navigation and positioning.

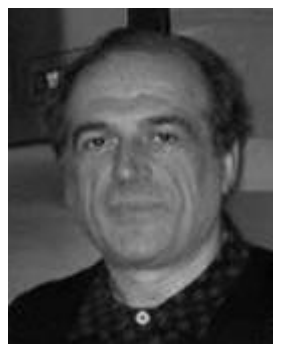

Antonio Corradi (M) graduated from University of Bologna, Italy, and received MS in electrical engineering from Cornell University, USA. He is a full professor of computer engineering at the University of Bologna. His research interests include distributed systems, pervasive and heterogeneous computing, context-aware services, network management, mobile agent platforms. He is member of IEEE, ACM, and Italian Association for Computing (AICA).

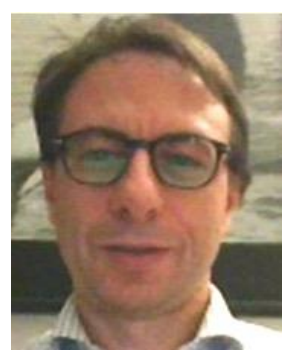

Stefano de Miranda graduated from the University of Bologna, Italy, where he received a Ph.D. degree in Mechanics of Structures in 2001. He is now Associate Professor of Mechanics of Solids and Structures at the University of Bologna. $\mathrm{He}$ is coordinator of the Master's Degree in Civil Engineering-UniBO, head of the Laboratory of Computational Mechanics, DICAM-UniBO and member of the Faculty of the Ph.D. Program in Civil, Environmental and Materials EngineeringUniBO. His research interests include numerical modelling and finite element approaches, computational wind engineering, coupled problems, historic masonry structures, environmental ageing of porous materials. He is the author of over 70 papers published in international peer-reviewed journals.

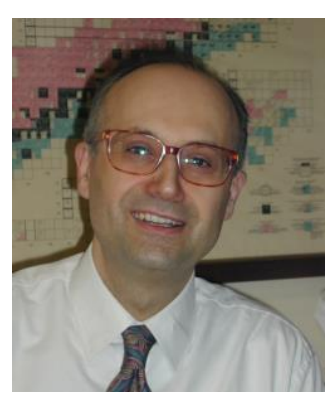

Fabio Fava (1963) is Full Professor of "Industrial \& Environmental Biotechnology" at the University of Bologna (Italy) since 2005. He has more than 140 papers on peerreviewed medium/high IF international journals in the field of Bioeconomy where he coordinated the FP7 projects NAMASTE and BIOCLEAN and participated in 7 other FP7 collaborative projects. $\mathrm{He}$ is the Italian Representative in the Working Party on "Biotechnology, Nanotechnology and Converging Technologies" at OECD (Paris) and at the European Commission (Brussels) in the: a) Horizon2020 Programming Committee "Bioeconomy" (SC2, DG RTD), b) "States Representatives Group" of the "Public Private Partnership BioBased Industry" (BBI JU), c) the "Expert Group on biobased products" (DG GROW), and d) BLUEMED initiative (Eu Med GSO; DG RTD). Finally, he is the scientific coordinator of the International Exhibition on Green and Circular Economy ECOMONDO (Rimini, Italy). 


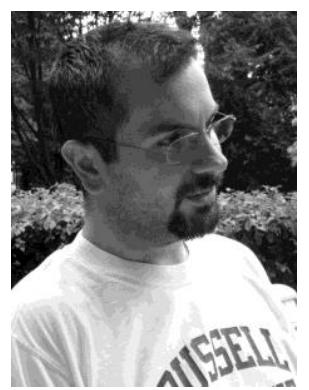

Luca Foschini (M) graduated from the University of Bologna, Italy, where he received a Ph.D. degree in computer science engineering in 2007. He is now an assistant professor of computer engineering at the University of Bologna. His interests span from integrated management of distributed systems and services to wireless pervasive computing and scalable context data distribution infrastructures and context-aware services. Currently, he is working on mobile crowdsensing and crowdsourcing and management of Cloud systems for Smart City environments.

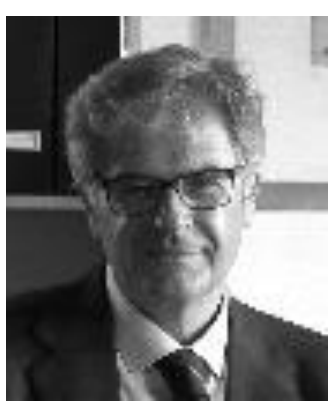

Giovanni Leoni Full Professor of History of Architecture at the University of Bologna, past Director of the DA and current coordinator of $\mathrm{Ph}$.D. Program in Architecture. He is a specialist in Modern Architecture and his books have been translated in English, Spanish, Portuguese, French and Chinese. member of AISTARCH, Italian Society of Architectural Historians. Member of the Scientific Committee of the Mapping Architectural Criticism (Agence Nationale de la Recherche, France) network. Coordinator of the working group "Culture" of Urban@it - National Study Centre in Urban Policies. In 2016 he has been appointed as a member of the Board of Guarantors for Participative Process for the Enhancement of Bologna's motorway and freeway bypass by Italian Ministry of Infrastructures and Transport.

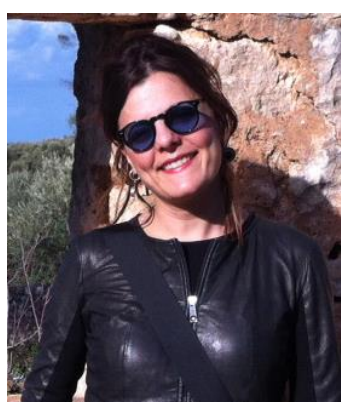

Danila Longo Architect, Ph.D., Associate Professor of Technology for Architecture. Member of the Department Council, Delegate for international researches and relations. Member of Ph.D. Committee, of SiTdA, of the Scientific Committee of GBC (Green Building Council -Italy). Member of international and national research groups with expertise in the fields of renovation processes of buildings and urban spaces, retrofitting of buildings, NZEBs, and mitigative initiatives related to climate change. She is member of EERA JPI on Smart Cities and UNIBO contact person for ECTPEnergy Efficient Buildings Committee.

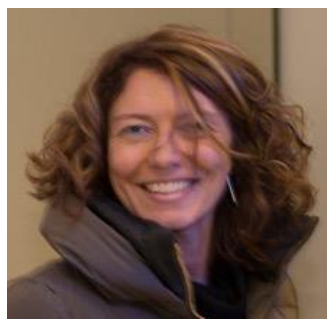

Michela Milano is full professor at the Department of Computer Science and Engineering, University of Bologna. Her research interests include theoretical and practical aspects of constraint reasoning, optimization and machine learning on application areas including planning and scheduling, computational sustainability, embedded system design, energy systems, industrial processes and Smart Cities. She is an author of more than 140 papers in International conferences and journals. She is the editor-in-chief of the Constraints Journal and area editor for INFORMS Journal on Computing and Constraint Programming Letters. She is member of the EurAI board and the AAAI executive council.

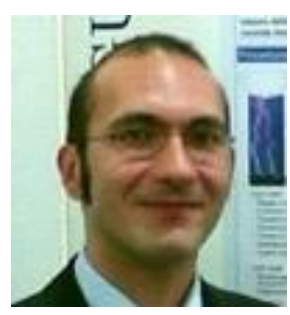

Fabio Napolitano (M'16-SM'17) is assistant professor at the Department of Electrical, Electronic and Information Engineering of the University of Bologna, Italy. From the same university, he received the M.S. degree (with hons.) in electrical engineering in 2003 and the Ph.D. degree in electrical engineering in 2009. Since his graduation he collaborated with the Power Systems group of the University of Bologna on the analysis of power systems transients, in particular those due to indirect lightning strokes, and lightning protection systems.

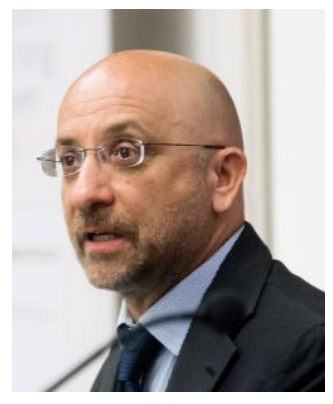

Carlo Alberto Nucci (M'91-SM'02F'07). Full professor and the head of the Power Systems Laboratory of the Department of Electrical, Electronic and Information Engineering 'Guglielmo Marconi,' University of Bologna, Bologna, Italy. He is author or coauthor of over 370 scientific papers published on peer-reviewed journals or on proceedings of international conferences. He is a Fellow of CIGRE, of which he is also honorary member, and has received some best paper/technical international awards, including the CIGRE Technical Committee Award and the ICLP Golde Award. From January 2006 to September 2012, he served as Chairman of Cigre Study Committee C4 'System Technical Performance.' He has served as IEEE PES Region 8 Rep in the years 2009 and 2010. Since January 2010 he serves as Editor-in-Chief of the Electric Power Systems Research journal, Elsevier. He has served as the President of the Italian Group of University Professors of Electrical Power Systems (GUSEE) from 2012 to 2015. He is an Advisor of the Global Resource Management Program of Doshisha University, Kyoto, supported by the Japanese Ministry of Education and Science, and has represented PES in the IEEE Smart City Initiatives Program since 2014. Prof. Nucci is doctor honoris causa of the University 'Politehnica' of Bucharest and member of the Bologna Science Academy.

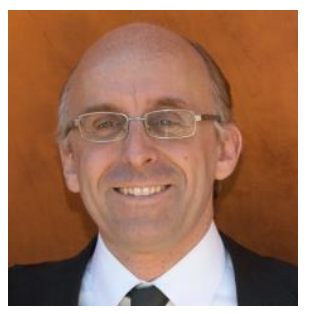

Gianni Pasolini (S'99 - M'03) received the M.Sc. degree in telecommunications engineering and the Ph.D. degree in electronic engineering and computer science from the University of Bologna, Italy, in 1999 and 2003, respectively. In October 2006, he became a researcher at the University of Bologna where he has been teaching telecommunications since 2003. Now he is with the Wireless Communication Laboratory (WiLAB) of the same 
University, where he is working on digital signal processing, wireless networks and intelligent transportation systems. He serves as reviewer for many Transactions/Journals and conferences and as TPC member of several international conferences.

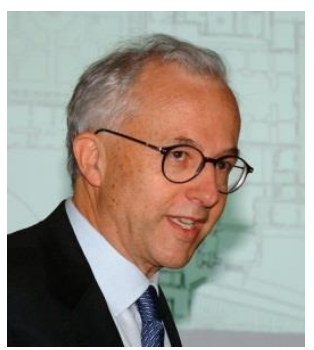

Tullio Salmon Cinotti was born in Bologna, Italy, on May 7th, 1950 and graduated in electrical engineering at the University of Bologna in 1974. He is Associate Professor at the School of Engineering and Architecture of the University of Bologna, and he is in charge of courses on computer architecture, logic design and interoperability of embedded systems. His research interests go from embedded systems to semantics based data distribution architectures for cyber-physical systems. He is co-author of researchers from Intel Labs, Nokia Research, Siemens Corporate Technology, Centro Ricerche Fiat, Telecom Italia Lab, VTT, Sintef, Politecnico di Milano, University of Kent. Tullio Salmon Cinotti is co-ordinator of the University of Bologna participation to European research initiatives focused on smart environments and IoT technologies, and on their application to societal challenges like open cultural heritage, electric mobility and water management. $\mathrm{He}$ is currently Director of ARCES, an inter-department research center of the University of Bologna.

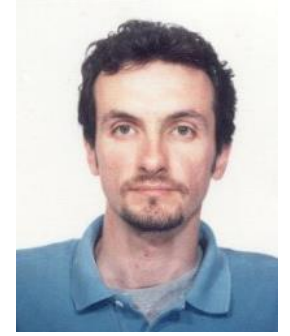

Marco Patella received the Laurea degree in electronic engineering and the $\mathrm{PhD}$ degree in electronic and computer engineering from the University of Bologna. Since 2006, he is an associate professor with the University of Bologna. His current research interests include similarity-and preference-based query processing in multimedia databases. He is one of the designers of the M-tree, an index for metric data.

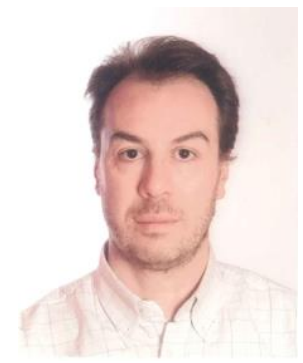

Daniele Tarchi [S'99, M'05, SM'12] was born in Florence, Italy, on 4th October 1975. He received his M.Sc. degree in telecommunications engineering and Ph.D. degree in informatics and telecommunications engineering from the University of Florence, Italy, in 2000 and 2004, respectively. From 2004 to 2010 he was a Research Associate with University of Florence, Italy. He is currently an Assistant professor at the University of Bologna, Italy. His research interest are mainly on resource allocation techniques, heterogeneous networks, Cognitive Radios and Networks, and Wireless Multimedia Networks, applied to both terrestrial and satellite wireless communications. Recently he has mainly focused on Smart City scenarios, multimedia systems, Fog Networks, and Smart Grid. $\mathrm{He}$ has been involved in several national and international research projects, and collaborates with several European research institutes; he is now the local research responsible for the project Gaucho (PRIN 2015). He has published more than 100 papers, among which more than 30 on international journals. Dr. Daniele Tarchi is an IEEE Senior Member since 2012. He is Editorial Board member for IEEE Wireless Communications Letters, IEEE Transactions on Vehicular Technology and IET Communications. He has been symposium co-chair for IEEE WCNC 2011, IEEE Globecom 2014 and IEEE Globecom 2018, and workshop co-chair at IEEE ICC 2015.

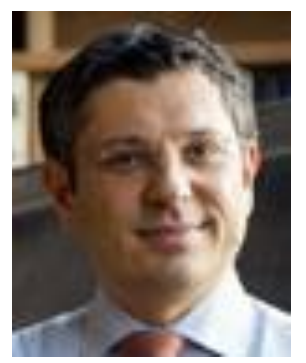

Francesco Ubertini graduated from the University of Bologna, Italy, where he received a Ph.D. degree in Mechanics of Structures in 1998. He is now full professor of Mechanics of Solids and Structures and Rector Magnificus of the University of Bologna. $\mathrm{He}$ is the President of Federico Zeri Foundation, of Fanti Melloni Foundation, of Bologna Business School Foundation, of Fibra Foundation and of the Board of the Confucius Institute at the University of Bologna. $\mathrm{He}$ is a member of the Academy of Sciences of the Institute of Bologna and of the Observatory of the Magna Charta Universitatum Council for the period 2016-2020. Prof. Francesco Ubertini was also a member of the Technical Committee on Computational Solid and Structural Mechanics, European Community on Computational Methods in Applied Sciences and coordinator of the Italian Group of Computational Mechanics (GIMC) and the Italian Association of Theoretical and Applied Mechatronics (AIMETA). His research interests include numerical modelling and finite element approaches, computational wind engineering, coupled problems, smart structures and advanced materials, historic masonry structures, environmental ageing of porous materials. He is the author of over 90 publications in international peer-reviewed journals and over 200 publications in proceedings of national and international conferences.

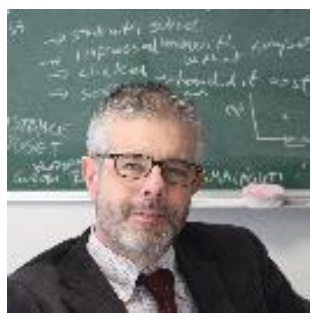

Daniele Vigo is Professor of Operations Research at the Department of Electrical, Electronic and Information Engineering of the University of Bologna. He is interested in the design of innovative algorithms for the solution of difficult decision and optimization problems arising in several applications fields ranging from Logistics to Energy Production and to Smart Cities. He is author of tens of scientific papers and coeditor of some highly cited books. He is president of the Italian OR society 2016-19 and coordinator of the EURO working group on Vehicle Routing and Logistics optimization. He has taken editorial responsibilities as: Associate editor of international journals: Transportation Science, Operations Research Letters and Operations Research. He has been editor of 3 international volumes and 6 special issues of international journals. He has been invited or keynote speaker at several conferences including OR2015 Vienna September 2015 and 4th winter school on Network Optimization, Estoril, Portugal, 1216 January 2015. 